\title{
Noncoding RNAs in gastric cancer: implications for drug resistance
}

Ling Wei ${ }^{1}$, Jujie Sun², Nasha Zhang ${ }^{3}$, Yan Zheng ${ }^{1}$, Xingwu Wang ${ }^{1}$, Liyan Lv', Jiandong Liu', Yeyang Xu', Yue Shen ${ }^{1}$ and Ming Yang ${ }^{1 *}$

\begin{abstract}
Gastric cancer is the fourth most common malignancy and the third leading cause of cancer-related deaths worldwide. Advanced gastric cancer patients can notably benefit from chemotherapy including adriamycin, platinum drugs, 5-fluorouracil, vincristine, and paclitaxel as well as targeted therapy drugs. Nevertheless, primary drug resistance or acquisition drug resistance eventually lead to treatment failure and poor outcomes of the gastric cancer patients. The detailed mechanisms involved in gastric cancer drug resistance have been revealed. Interestingly, different noncoding RNAs (ncRNAs), such as microRNAs (miRNAs), long noncoding RNAs (IncRNAs) and circular RNAs (circRNAs), are critically involved in gastric cancer development. Multiple lines of evidences demonstrated that ncRNAs play a vital role in gastric cancer resistance to chemotherapy reagents and targeted therapy drugs. In this review, we systematically summarized the emerging role and detailed molecular mechanisms of ncRNAs impact drug resistance of gastric cancer. Additionally, we propose the potential clinical implications of ncRNAs as novel therapeutic targets and prognostic biomarkers for gastric cancer.
\end{abstract}

Keywords: Gastric cancer, Drug resistance, MicroRNA, Long non-coding RNA, Circular RNA

\section{Background}

Gastric cancer is a malignant tumor originating from the gastric mucosa. As the fourth most common malignancy and the third leading cause of cancer-related deaths worldwide, there were about 984,000 new gastric cancer cases and 841,000 deaths occurred in 2013 [1]. Due to lack of obvious and specific symptoms at early disease stage, most gastric cancer patients were diagnosed at advanced disease stages with poor prognosis. The combined use of chemotherapy and targeted therapy has evidently prolonged the overall survival and improved life quality of gastric cancer patients with advanced disease. The commonly used chemotherapeutic agents include adriamycin (ADR), platinum drugs, 5-fluorouracil

\footnotetext{
* Correspondence: aaryoung@yeah.net

'Shandong Provincial Key Laboratory of Radiation Oncology, Cancer Research Center, Shandong Cancer Hospital and Institute, Shandong First Medical University and Shandong Academy of Medical Sciences, Jinan 250117, Shandong Province, China

Full list of author information is available at the end of the article
}

(5-FU), vincristine (VCR) and paclitaxel (PTX). However, the development of multi-drug resistance (MDR) of gastric cancer cells is a major hurdle in clinical oncology, which may result in a poor prognosis. The complicated mechanisms involved in gastric cancer MDR include inactivation of apoptosis signaling pathways, loss of cell cycle checkpoint control, accelerated cell proliferation and autophagy flux, enhanced DNA damage repair capacity, diminished uptake and/or increased efflux of drugs via upregulated MDR-associated proteins, activated cancer stem cells (CSCs), as well as epithelialmesenchymal transition (EMT) [2-4]. However, the detailed mechanisms of MDR remain inconclusive.

Noncoding RNAs (ncRNAs) are RNA transcripts encoding no proteins and are classified as small ncRNAs (sncRNAs, 18 200 nt) and long noncoding RNAs (lncRNAs, >200 nt). There are different kinds of sncRNAs, such as microRNAs (miRNAs), small nuclear RNAs (snRNAs), piwi interacting RNAs (piRNAs), and 
small nucleolar RNAs (snoRNAs) [5-15]. It has been found that ncRNAs are involved in almost all cellular functions, such as proliferation, apoptosis, EMT, autophagy and cell cycle control [16-20]. Multiple ncRNAs acts as oncogenes or tumor suppressor genes during carcinogenesis and can also serve as diagnostic and prognostic markers of cancer patients after certain therapies [21, 22]. In gastric cancer, a variety of abnormally expressed ncRNAs were identified to promote tumor progression, radioresistance, chemoresistance and targeted therapy sensitivity [23-28]. Interestingly, several miRNAs, IncRNAs and circRNAs have been found to play an essential part in gastric cancer drug resistance, especially in chemoresistance. However, there are still no studies how lncRNAs and circRNAs are involved in gastric cancer resistance to targeted therapy. Interestingly, it has been found that via sponging miR-331-3p in gastric cancer, lncRNA HOX transcript antisense gene RNA (HOTAIR) can regulate the expression of human epidermal growth factor receptor 2 (HER2), a target of targeted therapy agent [29]. Similarly, lncRNA H19 could regulate HER2 expression through sequestering let-7c in gastric cancer cells [30], indicating the potiential of ncRNAs may modulate sensitivity to targeted therapy.

Immunotherapy with immune checkpoint inhibitors for gastric cancer has emerged [31-37]. In gastric cancer, the relatively identified and useful population for immunotherapy is patients receiving third-line treatment. The commonly used immune-checkpoint blockade agents include anti-programmed cell death protein 1 (PD-1) monoclonal antibodies (Nivolumab and Pembrolizumab), anti-PD-L1 IgG1 antibody (Avelumab), as well as anti-CTLA-4 antibodies (Ipilimumab and Tremelimumab). Multiple parameters, such as microsatellite instability (MSI), mismatch repair (MMR) deficiency, high mutational load and high infiltrating CD8+ T cells density in tumor tissues can predict the response of solid tumors to immunotherapy [38-41]. To the best of our knowledge, there are no reports on miRNAs, lncRNAs and circRNAs involved in drug resistance to immunecheckpoint blockade agents in gastric cancer.

Herein, we performed a systematic literature review on the detailed mechanisms how ncRNAs intensify or weaken drug resistance of gastric cancer, which highlighting that ncRNAs may act as potential biomarkers and/or therapeutic targets of gastric cancer.

\section{MiRNAs and drug resistance}

MiRNAs are a class of sncRNAs of 19-24 nt in length, which could post-transcriptionally suppress gene expression via binding to the 3'-untranslated region (3'-UTR) of multiple target messenger RNAs (mRNAs) and/or other RNAs [42, 43]. Multiple miRNAs are dysregulated in gastric cancer and play a crucial role in tumorigenesis, cancer metastasis, as well as development of resistance to drugs and radiation [44-48]. It has been observed that significantly changed miRNA expression profiles in drug-resistant gastric cancer cells compared to those in drug-sensitive cells. The involvement of miRNAs in gastric cancer resistance to ADR, platinum drugs, 5-FU, VCR, PTX and other drugs is summarized below.

\section{MiRNAs and ADR resistance}

As a cell cycle non-specific anti-cancer antibiotic, ADR can inhibit the synthesis of nucleic acids through embedding into DNA and exert strong cytotoxic effects on tumor cells. In gastric cancer patients, ADR is commonly used in combination with platinum drugs, 5-FU, VCR, PTX and mitomycin. Multiple genes and miRNAs have been shown to be responsible for the development of ADR resistance in gastric cancer [49-53].

Several oncogenic miRNAs can promote ADR resistance in gastric cancer (Table 1). MiR-27a, for instance,

Table 1 MiRNAs and adriamycin resistance in gastric cancer

\begin{tabular}{|c|c|c|c|}
\hline MiRNAs & Expression $^{1}$ & Genes and Pathways & References \\
\hline miR-27a & $\uparrow$ & P-gp, cyclin D1, p21 & {$[54]$} \\
\hline miR-135a-5p & $\uparrow$ & $A P-2 a$ & {$[55]$} \\
\hline miR-BART20-5p & $\uparrow$ & Bad & {$[56]$} \\
\hline miR-19a/b & $\uparrow$ & PTEN & {$[57]$} \\
\hline miR-501 & $\uparrow$ & $B L I D$ & {$[58,59]$} \\
\hline miR-20a & $\uparrow$ & EGR2 & {$[60]$} \\
\hline $\operatorname{miR}-21-5 p$ & $\uparrow$ & PTEN,TIMP3 & {$[61]$} \\
\hline miR-633 & $\uparrow$ & FADD & {$[62]$} \\
\hline miR-520h & $\uparrow$ & $H D A C 1$ & {$[63]$} \\
\hline miR-129-5p & $\downarrow$ & $A B C B 1, A B C C 5, A B C G 1$ & [64] \\
\hline miR-508-5p & $\downarrow$ & $A B C B 1, Z N R D 1$ & {$[65]$} \\
\hline miR-103/107 & $\downarrow$ & $c a v-1, P-g p$ & {$[66]$} \\
\hline miR-27b, miR-508-5p & $\downarrow$ & $A B C B 1, C C N G 1, Z N R D 1$ & {$[67]$} \\
\hline miR-140 & $\downarrow$ & $A B C C 1, A B C G 2, S O X 4$ & {$[68]$} \\
\hline miR-107 & $\downarrow$ & P-gp, cyclin D1, c-myc & [69] \\
\hline miR-15b, miR-16 & $\downarrow$ & $B C l-2$ & [70] \\
\hline miR-181b & $\downarrow$ & $B C l-2$ & [71] \\
\hline miR-497 & $\downarrow$ & $B C l-2$ & [72] \\
\hline $\mathrm{miR}-200 \mathrm{bc} / 429$ & $\downarrow$ & $B C l-2, X I A P$ & [73] \\
\hline miR-34 & $\downarrow$ & BCl-2, Notch, HMGA2 & [74] \\
\hline miR-200c & $\downarrow$ & E-cadherin, Bax, BCl-2 & {$[75]$} \\
\hline miR-185 & $\downarrow$ & $A R C$ & {$[76]$} \\
\hline miR-126 & $\downarrow$ & $E Z H 2$ & {$[77]$} \\
\hline miR-218 & $\downarrow$ & $S M O$ & [78] \\
\hline miR-494 & $\downarrow$ & PDE4D & [79] \\
\hline
\end{tabular}

${ }^{1}$ miRNAs either up-regulated $(\uparrow)$ or down-regulated $(\downarrow)$ in adriamycin resistant gastric cancer cells

Note: This table shows 25 miRNAs whose expression levels and potential targets in adriamycin resistance of gastric cancer. 
has been found to confer ADR resistance by inhibiting multidrug resistance 1 (MDR1)/P-gp expression in gastric cancer cells [54]. Exogenous expression of miR135a-5p could enhance apoptosis resistance to ADR in gastric cancer cells via silencing activating protein 2 alpha (AP-2 $\alpha$ ) and, thus, upregulating Bcl-2 expression [55]. Interestingly, Epstein-Barr (EB) virus miRNA miRBART20-5p could also significantly increase ADR resistance of gastric cancer by inhibiting gene expression of BAD, a Bcl-2 family member [56]. MiR-19a/b, a member of the miR-17-92 cluster, is highly expressed in SGC7901/ADR resistant gastric cancer cell. It has been found that miR-19a/b promotes ADR resistance of gastric cancer via targeting and suppressing expression phosphatase and tensin homologue (PTEN). Meanwhile, miR-19a/b could accelerate ADR efflux of gastric cancer cells by increasing P-gp expression and inhibit apoptosis induced by ADR [57]. MiR-501 is another significantly up-regulated miRNA in SGC7901/ADR cells. MiR-501 could confer ADR resistance of gastric cancer via suppressing expression of BH3-like motif-containing protein, cell death inducer (BLID) [58]. Additionally, miR501 was also identified in SGC7901/ADR cells-secreted exosomes (ADR Exo) with a relatively high level. Exosome transferred miR-501 could promote tumorigenesis and ADR resistance through down-regulating BLID expression, and subsequently, inactivating phosphorylation of AKT and caspase-9/-3 [59]. MiR-20a was also proved to enhance gastric cancer resistance to ADR via inhibiting expression of early growth response 2 (EGR2), a member of a multi-gene family which encoding $\mathrm{C} 2 \mathrm{H} 2$ type zinc-finger proteins [60]. Through silencing PTEN and tissue inhibitor of matrix metalloproteinases 3 (TIMP3), miR-21-5p increases ADR resistance of gastric cancer cells [61]. It has also been found that miR-633 promotes ADR resistance of gastric cancer by inhibiting expression of Fas-associated death domain (FADD) [62]. In addition, epigenetics controlling mediated by miRNAs has been reported as an important signaling impacting tumorigenesis of gastric cancer. The histone deacetylase (HDAC) family plays a key role in epigenetics regulation of gastric cancer [80]. For example, it has been found that miR-520h down-regulated expression of HDAC1, which contributing to ADR resistance of gastric cancer [63].

By contrast, multiple tumor suppressor miRNAs can reverse ADR resistance of gastric cancer (Table 1). For instance, ectopic miR-129-5p expression can weaken the ADR resistance in gastric cancer cells SGC7901/ADR via silencing $\mathrm{ABCB} 1$ (ATP-binding cassette, subfamily B, member 1), ABCC5 and ABCG1 [64]. Similarly, exogenous expression of miR-508-5p has been found to reverse ADR resistance and decrease the intracellular concentration of chemotherapeutics by inhibiting expression of
$\mathrm{ABCB} 1$ and zinc ribbon domain-containing 1 (ZNRD1) [65]. Additionally, miR-103/107 has also been shown to inhibit P-gp function/expression and increase ADR sensitivity of SGC7901/ADR cells. Mechanically, caveolin-1 (cav-1), a key component of lipid rafts regulating P-gp activity, is considered as the direct target gene of miR103/107 [66]. Tumor suppressor miR-27b, miR-140 and miR-107, have also been confirmed to be involved in ADR resistance of gastric cancer by modulating expression/function of the $A B C$ transporters family members [67-69]. In addition to $A B C$ transporters, the Bcl-2 family also participate in chemoresistance of malignancies, including gastric cancer. Tumor suppressors miR-15b, miR-16, miR-181b and miR-497 could promote ADRinduced apoptosis of gastric cancer cells via silencing Bcl-2 expression [70-72]. MiRNAs encoded by the miR$200 \mathrm{bc} / 429$ cluster has also been found to function as inhibitors of ADR- resistant gastric cancer cells through inhibiting expression of $\mathrm{Bcl}-2$ and X-linked inhibitor of apoptosis (XIAP) [73]. Restoration of miR-34 in gastric cancer cells suppresses growth and increased apoptosis through down-regulating expression of $\mathrm{Bcl}-2$, Notch, and high-mobility group AT-hook 2 (HMGA2) [74]. Ectopic miR-200c could sensitize SGC7901/DDP cell to ADR, cisplatin (DDP) and 5-FU through suppressing expression of $\mathrm{Bcl}-2$ and Bax expression [75]. Additionally, significant reduced expression of tumor suppressors miR-185, miR-126, miR-218 and miR-494 in ADRresistant gastric cancer cells could diminish ADR sensitivity by silencing apoptosis repressor with caspase recruitment domain (ARC), enhancer of zeste homolog 2 (EZH2), smoothened (SMO, a transmembrane protein and member of Hedgehog pathway) and phosphodiesterase 4D (PDE4D), respectively [76-79].

\section{MiRNAs and resistance to platinum drugs}

Platinum drugs are a class of cell cycle non-specific drugs, which mainly form platinum-DNA adduction with DNA in cancer cells and result in necrosis or apoptosis of cancer cells. Due to their unique anticancer mechanisms and extensive anticancer spectrum, platinum drugs have been widely utilized in clinic $[81,82]$. Currently, platinum-based chemotherapy is a standard treatment for gastric cancer patients. There are a total of three generations of platinum drugs including cisplatin as the first-generation platinum drug, carboplatin as the second-generation platinum drugs, as well as oxaliplatin and loplatin as the third-generation platinum drugs. Multiple miRNAs have been reported to be involved in resistance to platinum drugs in gastric cancer (Table 2).

Several oncogenic miRNAs can promote resistance to platinum drugs in gastric cancer cells, such as miR-20a, miR-106a, miR-21, miR-25, miR-141, miR-223, miR-421, miR-99a, miR-491, and miR-27a. For example, miR-20a 
Table 2 MiRNAs and platinum drugs resistance in gastric cancer

\begin{tabular}{|c|c|c|c|c|}
\hline MiRNAs & Expression $^{1}$ & Genes and Pathways & Drugs & Reference \\
\hline \multirow[t]{2}{*}{ miR-20a } & $\uparrow$ & EGR2 & cisplatin & {$[60]$} \\
\hline & & CYLD & & [83] \\
\hline \multirow[t]{2}{*}{ miR-106a } & $\uparrow$ & PTEN/Akt & cisplatin & {$[84]$} \\
\hline & & RUNX & & {$[85]$} \\
\hline miR-21 & $\uparrow$ & PTEN/Akt & cisplatin & {$[86]$} \\
\hline miR-25 & $\uparrow$ & FOXO3a & cisplatin & {$[87]$} \\
\hline miR-141 & $\uparrow$ & KEAP1 & cisplatin & {$[88]$} \\
\hline miR-223 & $\uparrow$ & FBXW7 & cisplatin & {$[89]$} \\
\hline miR-99a, miR-491 & $\uparrow$ & CAPNS1 & cisplatin & {$[90]$} \\
\hline miR-421 & $\uparrow$ & E-cadherin, caspase-3 & cisplatin & {$[91]$} \\
\hline miR-135b-5p & $\uparrow$ & KLF4 & cisplatin & {$[92]$} \\
\hline miR-135b & $\uparrow$ & MST1, MAPK & cisplatin & [93] \\
\hline miR-17-5p & $\uparrow$ & p21 & cisplatin & {$[94]$} \\
\hline miR-193a-3p & $\uparrow$ & SRSF2 & cisplatin & {$[28]$} \\
\hline miR-4295 & $\uparrow$ & $L R|G|$ & cisplatin & {$[95]$} \\
\hline miR-3174 & $\uparrow$ & ARHGAP10 & cisplatin & {$[96]$} \\
\hline miR-27a & $\uparrow$ & $P-g p, L R P, B C l-2$ & oxaliplatin & {$[97]$} \\
\hline miR-135a & $\uparrow$ & E2F1, DAPK2 & oxaliplatin & {$[98]$} \\
\hline miR-27b, miR-508-5p & $\downarrow$ & $A B C B 1, C C N G 1$, ZNRD1 & cisplatin & {$[67]$} \\
\hline miR-129-5p & $\downarrow$ & $A B C B 1, A B C C 5, A B C G 1$ & cisplatin & {$[64]$} \\
\hline miR-508-5p & $\downarrow$ & $A B C B 1$, ZNRD1 & cisplatin & {$[65]$} \\
\hline miR-129 & $\downarrow$ & $P-g p$ & cisplatin & [99] \\
\hline miR-107 & $\downarrow$ & P-gp, cyclin D1, c-myc & oxaliplatin & {$[69]$} \\
\hline miR-15b, miR-16 & $\downarrow$ & $B C l-2$ & cisplatin & {$[70]$} \\
\hline miR-181b & $\downarrow$ & $B C l-2$ & cisplatin & {$[71]$} \\
\hline miR-497 & $\downarrow$ & $B C l-2$ & cisplatin & {$[72]$} \\
\hline miR-200bc/429 cluster & $\downarrow$ & $B C l-2, X I A P$ & cisplatin & {$[73]$} \\
\hline miR-34 & $\downarrow$ & BCl-2, Notch, HMGA2 & cisplatin & {$[74]$} \\
\hline miR-449a & $\downarrow$ & $B C l-2, C C D N 1$ & cisplatin & {$[100]$} \\
\hline miR-1271 & $\downarrow$ & IGFIR, IRSI, mTOR, BCl-2 & cisplatin & [101] \\
\hline miR-143 & $\downarrow$ & $I G F 1 R, B C \mid-2$ & cisplatin & [102] \\
\hline miR-503 & $\downarrow$ & IGFIR, BCl-2 & cisplatin & [103] \\
\hline miR-23b-3p & $\downarrow$ & ATG12, HMGB2 & cisplatin & [104] \\
\hline miR-181a & $\downarrow$ & ATG5 & cisplatin & {$[105]$} \\
\hline miR-30 & $\downarrow$ & LC3-II & cisplatin & [106] \\
\hline miR-148a-3p & $\downarrow$ & RAB12, mTOR1, AKAP1 & cisplatin & [107] \\
\hline \multirow[t]{3}{*}{ miR-200c } & $\downarrow$ & E-cadherin & cisplatin & {$[75]$} \\
\hline & & RhoE & & [108] \\
\hline & & ZEB2 & & [109] \\
\hline \multirow[t]{2}{*}{ miR-101 } & $\downarrow$ & ANXA2 & cisplatin & [110] \\
\hline & & VEGF-C & & [111] \\
\hline \multirow[t]{2}{*}{ miR-218 } & $\downarrow$ & $m T O R$ & cisplatin & [112] \\
\hline & & $S M O$ & oxaliplatin & [78] \\
\hline miR-185 & $\downarrow$ & $A R C$ & cisplatin & {$[76]$} \\
\hline
\end{tabular}


Table 2 MiRNAs and platinum drugs resistance in gastric cancer (Continued)

\begin{tabular}{|c|c|c|c|c|}
\hline MiRNAs & Expression $^{1}$ & Genes and Pathways & Drugs & Reference \\
\hline miR-34a & $\downarrow$ & MET & cisplatin & [113] \\
\hline miR-26a & $\downarrow$ & NRAS, E2F2 & cisplatin & [114] \\
\hline miR-149 & $\downarrow$ & FoxM1 & cisplatin & [115] \\
\hline miR-524-5p & $\downarrow$ & SOX9 & cisplatin & [116] \\
\hline miR-362-5p & $\downarrow$ & SUZ12 & cisplatin & [117] \\
\hline miR-198 & $\downarrow$ & FGFR1 & cisplatin & [118] \\
\hline miR-574-3p & $\downarrow$ & ZEB1 & cisplatin & [119] \\
\hline miR-876-3p & $\downarrow$ & TMED3 & cisplatin & [120] \\
\hline miR-874 & $\downarrow$ & ATG16L1 & cisplatin & [121] \\
\hline let-7b & $\downarrow$ & $A \cup R K B$ & cisplatin & [122] \\
\hline miR-122 & $\downarrow$ & ERCC1 & cisplatin & [123] \\
\hline miR-138-5p & $\downarrow$ & ERCC1, ERCC4 & cisplatin & [48] \\
\hline miR-192-5p & $\downarrow$ & ERCC3, ERCC4 & cisplatin & [124] \\
\hline
\end{tabular}

${ }^{1}$ miRNAs either up-regulated $(\uparrow)$ or down-regulated $(\downarrow)$ in platinum drugs resistant gastric cancer cells

Note: This table shows 53 miRNAs whose expression levels and potential targets in platinum drugs resistance of gastric cancer.

could confer DDP resistance by silencing EGR2 and cylindromatosis (CYLD) in gastric cancer cells $[60,83]$. Exogenous expression of miR-106a enhanced the resistance to DDP of gastric cancer cells by inhibiting the PTEN/Akt signaling pathway and tumor suppressive RUNX3 [84, 85]. Similarly, miR-21 has also been found to promote DDP resistance via silencing the PTEN/Akt pathway, while contrary results were observed after administration of PI3K inhibitors suppressing Akt pathway [86]. MiR-25, miR-141 and miR-223, which are significantly up-regulated in SGC-7901/DDP resistant gastric cancer cells, could enhance DDP resistance via suppressing expression levels of FOXO3a, kelch-like ECHassociated protein-1(KEAP1) and F-Box and WD repeat domain containing 7 (FBXW7), respectively [87-89]. MiR-99a and miR-491, which are also overexpressed in SGC-7901/DDP and BGC-823/DDP resistant gastric cancer cells, could promote DDP resistance by directly down-regulating their target gene, calpain small subunit 1 (CAPNS1) [90]. MiR-421, a highly expressed miRNA in advanced gastric cancer patients, could also promote gastric cancer metastasis and DDP resistance through inhibiting E-cadherin and caspase-3 expression, in vivo and in vitro [91]. In addition, oncogenic miR-135b-5p, miR-135b, miR-17-5p, miR-193a-3p, miR-4295 and miR3174 confer DDP resistance of gastric cancer cells through silencing Krüppel-like factor 4 (KLF4), mammalian ste20-like kinase 1 (MST1), p21, SRSF2, leucine-rich repeats and immunoglobulin-like domains 1 (LRIG1) and ARHGAP10, respectively [28, 92-96]. For oxaliplatin resistance, the oncogenic miR-27a has been found to enhance MDR properties by inducing MDR1/P-gp, lung resistance protein (LRP) and $\mathrm{Bcl}-2$ expression in gastric cancer [97]. Similarly, miR-135a has also been shown to potentiate oxaliplatin resistance of gastric cancer cells by down-regulating expression of E2F transcription factor 1 (E2F1) and death-associated protein kinase 2 (DAPK2) [98].

Conversely, a number of tumor suppressor miRNAs can reverse platinum drugs resistance of gastric cancer. For instance, miR-27b, miR-508-5p, miR-129-5p and miR-129, have been found to reverse gastric cancer resistance to DDP mainly through affecting expression/ function of the $\mathrm{ABC}$ transporters family members [64, $65,67,99]$. Similarly, miR-107 has been found to increase the sensitivity of gastric cancer cells to oxaliplatin through inhibiting expression of P-gp, cyclin D1 and cmyc [69]. By inhibiting the Bcl-2 signaling pathway, several tumor suppressor miRNAs, including miR-15b, miR-16, miR-181b, miR-497, the miR-200bc/429 cluster, miR-34 as well as miR-449a, have been found to sensitize gastric cancer cells to DDP [70-74, 100]. Activation of the IGF1R/IRS1 pathway has also been identified to promote drug resistance of multiple malignancies, including gastric cancer. A variety of miRNAs, such as miR-1271, miR-143 and miR-503, have been observed to be involved in the IGF1R/IRS1 pathway-mediated DDP resistance of gastric cancer [101-103]. Recently, emerging evidences indicate that miRNAs are involved in MDR controlling by regulating autophagy through targeting autophagy related genes. In gastric cancer, for example, exogenous overexpression of miR-23b-3p has been found to reverse DDP resistance by modulating expression of autophagy related 12 (ATG12) and high mobility group box 2 (HMGB2) [104]. Similarly, miR-181a, miR-30 and miR-148a-3p have been found to enhance DDP sensitivity of gastric cancer cells through suppressing expression of ATG5, 
LC3-II, RAB12 and mTOR1, respectively [105-107]. In addition, ectopic miR-200c has been found to sensitize SGC7901/DDP resistance gastric cancer cells to DDP through inhibiting expression of E-cadherin, Rho family GTPase 3 (RhoE) and ZEB2 [75, 108, 109]. By modulating Annexin A2 (ANXA2) and VEGF-C expression, tumor suppressor miR-101 has been found to reverse DDP resistance of gastric cancer cells [110, 111]. As for miR-218, its overexpression has been found to enhance sensitivity to DDP and oxaliplatin by targeting mTOR and SMO, respectively [78, 112]. Moreover, exogenous expression of tumor suppressor miR-185, miR-34a, miR26a, miR-149 and miR-524-5p in gastric cancer cells can also improve DDP sensitivity. Their potential target genes are ARC, mesenchymal-epithelial transition factor (MET), neuroblastoma RAS viral oncogene homolog (NRAS), E2F transcription factor 2 (E2F2), Forkhead box M1 (FoxM1) and SOX9, respectively [76, 113-116]. Similarly, tumor suppressor miR-362-5p, miR-198, miR574-3p, miR-876-3p, miR-874 and let-7b have been reported to reverse DDP resistance of gastric cancer cells via silencing suppressor of zeste 12 protein (SUZ12), fibroblast growth factor receptor 1 (FGFR1), zinc finger E-box binding homeobox transcription factor 1 (ZEB1), TMED3, autophagy-related 16-like 1 (ATG16 L1) and AURKB, respectively [117-122]. In addition, via targeting excision repair cross-complementing (ERCC), exogenous over-expression of tumor suppressor miR-122, miR-138-5p and miR-192-5p could also reverse DDP resistance of gastric cancer [48, 123, 124].

\section{MiRNAs and 5-FU resistance}

5-FU is commonly applied for the treatment of gastric cancer in clinic. 5-FU could disturb DNA replication via suppressing thymidylate synthase (TS), thereby leading to apoptosis and cell cycle arrest $[125,126]$. It has been found that multiple oncogenic or tumor suppressive miRNAs are involved in 5-FU resistance (Table 3).

Several oncogenic miRNAs promote 5-FU resistance of gastric cancer cells, such as miR-BART20-5p, miR193a-3p, miR-147 and miR-17. It has been found that EB virus miRNA miR-BART20-5p significantly increased 5-FU resistance of AGS1 gastric cancer cells by inhibiting BAD expression [56]. Similarly, miR-193-3p and miR-147 could promote 5-FU resistance of gastric cancer cells via directly suppressing their target gene PTEN $[127,128]$. Oncogenic miR-17 has been found to reduce 5-FU sensitivity of gastric cancer cells through silencing expression of DEDD [129].

On the contrary, several tumor suppressor miRNAs can reverse 5-FU resistance of gastric cancer. Accumulated evidences indicate that elevated expression of MDR-related ABC transporters confer 5-FU resistance. It has, for example, been found that tumor suppressor
Table 3 MiRNAs and 5-FU resistance in gastric cancer

\begin{tabular}{|c|c|c|c|}
\hline MiRNAs & Expression $^{1}$ & Genes and Pathways & Reference \\
\hline miR-BART20-5p & $\uparrow$ & $B A D$ & {$[56]$} \\
\hline miR-193-3p & $\uparrow$ & PTEN & {$[127]$} \\
\hline miR-147 & $\uparrow$ & PTEN & [128] \\
\hline miR-17 & $\uparrow$ & $D E D D$ & [129] \\
\hline miR-129-5p & $\downarrow$ & $A B C B 1, A B C C 5, A B C G 1$ & {$[64]$} \\
\hline miR-508-5p & $\downarrow$ & $A B C B 1$, ZNRD1 & {$[65]$} \\
\hline miR-27b, miR-508-5p & $\downarrow$ & $A B C B 1, C C N G 1$, ZNRD1 & {$[67]$} \\
\hline miR-107 & $\downarrow$ & P-gp, cyclin D1, c-myc, & {$[69]$} \\
\hline miR-181b & $\downarrow$ & $B C l-2$ & {$[71]$} \\
\hline miR-429 & $\downarrow$ & $B C l-2$ & [130] \\
\hline miR-200c & $\downarrow$ & E-cadherin & {$[75]$} \\
\hline miR-218 & $\downarrow$ & $S M O$ & {$[78]$} \\
\hline miR-23b-3p & $\downarrow$ & ATG12, HMGB2 & [104] \\
\hline \multirow[t]{3}{*}{ miR-31 } & $\downarrow$ & RhoA & [131] \\
\hline & & $\mathrm{ZH} 2$ & [132] \\
\hline & & E2F6, SMUG1 & [133] \\
\hline miR-197 & $\downarrow$ & MAPK1 & [134] \\
\hline miR-BART15-3p & $\downarrow$ & TAX1BP1 & [135] \\
\hline miR-195-5p & $\downarrow$ & ZNF139 & [136] \\
\hline miR-204 & $\downarrow$ & TGFBR2 & [137] \\
\hline miR-623 & $\downarrow$ & CCND1 & [138] \\
\hline miR-939 & $\downarrow$ & SLC34A2/Raf/MEKJERK & [139] \\
\hline miR-124 & $\downarrow$ & $E Z H 2$ & [140] \\
\hline
\end{tabular}

${ }^{1}$ miRNAs either up-regulated $(\uparrow)$ or down-regulated $(\downarrow)$ in 5-FU resistant gastric cancer cells

Note: This table shows 21 miRNAs whose expression levels and potential targets in 5-FU resistance of gastric cancer.

miR-27b, miR-508-5p, miR-129-5p and miR-107 could inhibit expression of certain family member of $A B C$ transporters and, thus, enhance sensitivity of gastric cancer cells to 5-FU $[64,65,67,69]$. MiR-181b, which is significantly down-regulated in MDR SGC7901/VCR cells, could sensitize gastric cancer cells to VCR and 5-FU through suppressing expression of Bcl-2 [71]. Similarly, Bcl-2 silencing by miR- 429 has also been found to sensitize gastric cancer cells to 5-FU [130]. In addition, over-expression of miR-23b-3p, an autophagy-related modulator, has been found to sensitize gastric cancer cells to 5-FU by inhibiting expression of ATG12 and HMGB2 [104]. MiR-31, a pleomorphic tumor suppressor miRNA, has been shown to impair 5-FU resistance of gastric cancer cells via silencing RhoA, zeste homolog 2 (ZH2), E2F6 and SMUG1 [131-133]. Additionally, exogenous expression of miR-197 and miR-BART15-3p could also strongly promote 5 -FU chemosensitivity through down-regulating expression of mitogenactivated protein kinase 1 (MAPK1) and Tax1-binding protein 1 (TAX1BP1), respectively [134, 135]. Tumor 
suppressor miR-195-5p, miR-204, miR-623, miR-939 and miR-124 have been shown to be involved in overcoming 5-FU resistance of gastric cancer via silencing Zing finger 139 (ZNF139), TGFBR2, cyclin D1 (CCND1), solute carrier family 34 member 2 (SLC34A2) and EZH2, respectively [136-140].

\section{MiRNAs and VCR resistance}

As an anti-microtubule drug, VCR could inhibit tubulin polymerization and disable spindles formation, which leading to mitosis arrest of malignant cells. It has been found that several oncogenic or tumor suppressive miRNAs are involved in VCR resistance (Table 4).

On one hand, oncogenic miR-19a/b has been reported to enhance VCR resistance of gastric cancer cells by suppressing expression of its target gene PTEN [57]. On the other hand, multiple tumor suppressor miRNAs have been found to be able to reverse VCR resistance of gastric cancer. For example, miR-129-5p, miR-508-5p and miR27b could sensitize resistance gastric cancer cells to VCR via silencing members of $A B C$ transporters [64, 65, 67]. Similarly, tumor suppressor miR-15b, miR-16, miR-181b, miR-497 and the miR-200bc/429 cluster have been found to increase VCR sensitivity through targeting the $\mathrm{Bcl}-2$ family members [70-73]. In addition, ectopic expression of miR-126, miR-647 and miR-1284, which are evidently downregulated in drug-resistant SGC7901/VCR gastric cancer cells, could sensitize gastric cancer cells to VCR by inhibiting expression of EZH2, ANK2 and EIF4A1, respectively [77, 141, 142]. In addition, miR-23b-3p and miR-101 are able to reverse drug resistance of gastric cancer cells to multiple chemotherapeutics including VCR via targeting ATG12/HMGB2 as well as ANXA2 [104, 110].

Table 4 MiRNAs and vincristine resistance in gastric cancer

\begin{tabular}{llll}
\hline MiRNAs & Expression $^{1}$ & Genes and Pathways & Reference \\
\hline miR-19a/b & $\uparrow$ & PTEN & {$[57]$} \\
miR-129-5p & $\downarrow$ & ABCB1, ABCC5, ABCG1 & {$[64]$} \\
miR-508-5p & $\downarrow$ & ABCB1, ZNRD1 & {$[65]$} \\
miR-27b, miR-508-5p & $\downarrow$ & CCNG1, ABCB1, ZNRD1 & {$[67]$} \\
miR-15b, miR-16 & $\downarrow$ & BCl-2 & {$[70]$} \\
miR-181b & $\downarrow$ & BCl-2 & {$[71]$} \\
miR-497 & $\downarrow$ & BCl-2 & {$[72]$} \\
miR-200bc/429 cluster & $\downarrow$ & BCl-2, XIAP & {$[73]$} \\
miR-126 & $\downarrow$ & EZH2 & {$[77]$} \\
miR-647 & $\downarrow$ & ANK2 & {$[141]$} \\
miR-1284 & $\downarrow$ & EIF4A1 & {$[142]$} \\
miR-23b-3p & $\downarrow$ & ATG12, HMGB2 & {$[104]$} \\
miR-101 & $\downarrow$ & ANXA2 & {$[110]$}
\end{tabular}

${ }^{1}$ miRNAs either up-regulated $(\uparrow)$ or down-regulated $(\downarrow)$ in vincristine resistant gastric cancer cells

Note: This table shows 14 miRNAs whose expression levels and potential targets in vincristine resistance of gastric cancer.

\section{MiRNAs and PTX resistance}

PTX is a highly effective cytotoxin to tubulin and can "freeze" the mitotic spindle apparatus of rapidly divided cancer cells, which leading to G2/M cell cycle arrest. PTX is one of the first-line chemotherapeutic reagents to treat gastric cancer. A variety of miRNAs have been reported to be involved in PTX resistance of gastric cancer (Table 5).

Several oncogenic miRNAs can promote PTX resistance, such as miR-21, miR-23a and miR-155-5p. A significantly elevated miR-21 expression was observed in PTX resistant SGC7901/PTX gastric cancer cells compared to the parent SGC7901 cells. MiR-21 could dramatically inhibit apoptosis induced by PTX, partly through regulating P-gp expression [143]. MiR-23a, which is dramatically up-regulated in human gastric cancer tissues, has been shown to weaken PTX-induced apoptosis and accelerate proliferation of BGC823 and MGC803 gastric cancer cells via suppressing expression of interferon regulator factor 1 (IRF1) [144]. In addition, exogenous expression of miR-590-5p has been found to impair PTX sensitivity of gastric cancer cells by silencing RECK and the AKT/ERK signaling pathway [145]. Recently, miR-155-5p was identified as an enriched miRNA in exosomes deriving from PTX-resistant MGC-803R gastric cancer cells. Exogenous expression of miR-155$5 \mathrm{p}$ confers chemoresistance and EMT in PTX-sensitive MGC-803S cells through targeting and suppressing GATA binding protein 3 (GATA3) and tumor protein p53-inducible nuclear protein 1 (TP53INP1) [146].

Meanwhile, multiple tumor suppressor miRNAs have been found to be able to reverse PTX resistance in gastric cancer. For instance, miR-34c-5p, which was found to be significantly down-regulated in PTX-resistant gastric cancer tissues, could sensitize SGC7901/VCR resistant cells to PTX via targeting and suppressing microtubule-associated protein tau (MAPT) [147]. Tumor suppressor miR-34a has also been shown to sensitize gastric cancer cells to PTX via inhibiting expression of oncoprotein E2F5 [148]. Similarly, ectopic

Table 5 MiRNAs and paclitaxel resistance in gastric cancer

\begin{tabular}{|c|c|c|c|}
\hline MiRNAs & Expression $^{1}$ & Genes and Pathways & Reference \\
\hline miR-21 & $\uparrow$ & $P-g p$ & {$[143]$} \\
\hline miR-23a & $\uparrow$ & IRFI & [144] \\
\hline miR-590-5p & $\uparrow$ & $R E C K, A K T, E R K$ & {$[145]$} \\
\hline miR-155-5p & $\uparrow$ & GATA3, TP53INP1 & {$[146]$} \\
\hline miR-34c-5p & $\downarrow$ & MAPT & [147] \\
\hline miR-34a & $\downarrow$ & E2F5 & {$[148]$} \\
\hline miR-495 & $\downarrow$ & $A B C B 1$ & [149] \\
\hline
\end{tabular}


expression of tumor suppressor miR-495 has been found to potentiate PTX-ADR sensitivity in MDR SGC7901R gastric cancer cells through modulating expression of ABCB1 [149].

\section{MiRNAs and resistance to targeted therapy drugs}

Target-therapy provides new therapeutic strategies for advanced gastric cancer. Multiple targeted therapy drugs have been developed to treat cancers including gastric cancer, such as cetuximab and panitumumab (anti-EGFR monoclonal antibodies [MoAbs]), trastuzumab and pertuzumab (anti-HER2 MoAbs), lapatinib (anti-HER2 and EGFR tyrosine kinase dual inhibitor), bevacizumab (antiVEGF-A MoAb) and ramucirumab (anti-VEGFR-2 MoAb). Among these drugs, trastuzumab and ramucirumab have been found to improve prognosis of advanced gastric cancer patients [34, 150-153]. Emerging evidences have demonstrated that several miRNAs have been involved in resistance to targeted therapy drugs in gastric cancer, such as trastuzumab and lapatinib (Table 6).

Trastuzumab, a US Food and Drug Administration (FDA) approved anti-human HER2 MoAb, combined with conventional chemotherapy has been broadly used in advanced or metastatic gastric cancer patients with HER2 overexpression/amplification. Through inhibiting PTEN expression, oncogenic miR-21 has been found to confer trastuzumab resistance in HER2-positive gastric cancer cells [154]. MiR-125b, which is markedly upregulated in gastric cancer tissues, is significantly associated with trastuzumab resistance and poor prognosis in HER2-positive gastric cancer patients [155]. Similarly, oncogenic miR-223 could decrease trastuzumab sensitivity of gastric cancer through suppressing expression of FBXW7 [156]. In addition, exogenous expression of tumor suppressor miR-200c has been found to sensitize gastric cancer cells to trastuzumab by targeting and downregulating ZEB1 and ZEB2 [157]. Similarly, through modulating cyclin $\mathrm{J}(\mathrm{CCNJ})$ and far upstream element-binding protein 1 (FUBP1), exogenous expression of miR-16 could reverse the resistance to trastuzumab and lapatinib in HER2 positive gastric cancer cells [158]. For lapatinib resistance, it has been reported that tumor suppressor miR-494 could not only reverses lapatinib resistance but also inhibit formation of cancerinitiating cells (CICs) via down-regulating expression of receptor tyrosine kinase fibroblast growth factor receptor 2 (FGFR2) in HER2-positive, FGFR2 overexpressing and lapatinib resistant YCC1-F gastric cancer cells [159].

\section{MiRNAs and resistance to other drugs}

Etoposide, mitomycin and capecitabine are also commonly used to treat gastric cancer. Several miRNAs are involved in resistance resistance to these drugs (Table 7). It has been found that by targeting and suppressing Bcl-2 expression, tumor suppressor miR15b, miR-16, miR-181b, miR-497 and the miR-200bc/ 429 cluster could sensitize gastric cancer cells to etoposide or mitomycin [70-73]. Significantly increased plasma miR-17-92 cluster levels has been found in advanced gastric cancer patients. Whereas, there was obvious decrease of these miRNAs in chemosensitive individuals after oxaliplatin/capecitabine (XELOX) chemotherapy, indicating they might be used as biomarkers of XELOX treatment [160].

\section{LncRNAs and chemoresistance}

LncRNAs are a class of ncRNAs longer than $200 \mathrm{nt}$ and have no protein coding potential. LncRNAs play a part in regulating various cellular processes. A number of IncRNAs have been identified to be abnormally expressed in gastric cancer and involved in chemoresistance via regulation of different target genes. Several oncogenic lncRNAs, such as prostate cancer-associated transcript 1 (PCAT-1), SNHG5, BCAR4, GHET1, HOTAIR, plasmacytoma variant translocation 1 (PVT1), metastasis-associated lung adenocarcinoma transcript 1 (MALAT1), urothelial carcinoma-associated 1 (UCA1) and nuclear paraspeckle assembly transcript 1 (NEAT1), as well as some tumor suppressor lncRNAs, have been shown to participate in gastric cancer chemoresistance.

\section{LncRNAs and resistance to platinum drugs}

Multiple (Table 8). For instance, lncRNA PCAT-1, a highly expressed lncRNA in DDP-resistant gastric cancer

Table 6 MiRNAs and targeted therapy drugs resistance in gastric cancer

\begin{tabular}{lllll}
\hline MiRNAs & Expression $^{1}$ & Genes and Pathways & Drugs & Reference \\
\hline miR-21 & $\uparrow$ & PTEN & trastuzumab & [154] \\
miR-125b & $\uparrow$ & & trastuzumab & [155] \\
miR-223 & $\uparrow$ & FBXW7 & trastuzumab & [156] \\
miR-200c & $\downarrow$ & ZEB1, ZEB2 & trastuzumab & [157] \\
miR-16 & $\downarrow$ & CCNJ, FUBP1 & trastuzumab, lapatinib & [158] \\
miR-494 & $\downarrow$ & FGFR2 & lapatinib & [159] \\
\hline
\end{tabular}

${ }^{1}$ miRNAs either up-regulated $(\uparrow)$ or down-regulated $(\downarrow)$ in targeted drugs resistant gastric cancer cells

Note: This table shows 6 miRNAs whose expression levels and potential targets in targeted therapy drugs resistance of gastric cancer. 
Table 7 miRNAs and resistance to other drugs in gastric cancer

\begin{tabular}{lllll}
\hline MiRNAs & Expression $^{1}$ & Genes and Pathways & Drugs & Reference \\
\hline miR-15b, miR-16 & $\downarrow$ & $B C l-2$ & etoposide, mitomycin & [70] \\
miR-181b & $\downarrow$ & $B C l-2$ & etoposide & [71] \\
miR-497 & $\downarrow$ & $B C l-2$ & etoposide & [72] \\
miR-200bc/429 cluster & $\downarrow$ & $B C l-2, X I A P$ & etoposide & [73] \\
miR-17-92 cluster & $\uparrow$ & & oxaliplatin/capecitabine & [160] \\
\hline
\end{tabular}

${ }^{1}$ miRNAs either up-regulated $(\uparrow)$ or down-regulated $(\downarrow)$ in other chemo-drugs resistant gastric cancer cells

Note: This table shows 6 miRNAs whose expression levels and potential targets in other chemo-drugs resistance of gastric cancer.

tissues and cells, promotes DDP resistance of gastric cancer cells via epigenetically suppressing PTEN expression by recruiting EZH2, as well as regulating the miR-128/ ZEB1 axis [161, 162]. Similarly, an evidently high expression lncRNA DANCR has been identified in SGC7901/ DDP and BGC823/DDP DDP-resistant gastric cancer cells. Knockdown of DANCR in these cells promote apoptosis and inhibit cell proliferation. On the contrary, overexpressed DANCR could up-regulated expression of MDR genes MDR1 and MRP1 in DDP-induced SGC901 and BGC823 cells [163]. LncRNA SNHG5 reduced DDP sensitivity of BGC823 and SGC7901 gastric cancer cells through up-regulating expression of MDR1, MRP1 and Bax as well as downregulating Bcl-2 expression [164]. In addition, IncRNAs GHET 1[165], AK022798 [166], antisense non-coding RNA in the INK4 locus (ANRIL) [167], UCA 1[168] and HULC [169] also conferred DDP resistance of gastric cancer cells via modulating expression of multiple drug resistance-related genes. LncRNA HOTAIR, which was significantly up-regulated in DDPresistant gastric cancer cells and tissues, could regulate chromatin status and contribute to DDP resistance of gastric cancer, through activating PI3K/Akt/MRP1 and Wnt/ $\beta$-catenin signaling pathways $[170,171]$. Interestingly, lncRNA XLOC_006753, which is highly expressed in gastric cancer patients and MDR SGC-7901/DDP gastric cancer cells, could promote resistance to DDP through regulating the $\mathrm{PI} 3 \mathrm{~K} / \mathrm{AKT} / \mathrm{mTOR}$ pathway [172]. OncolncRNAs zinc finger antisense 1 (ZFAS1) and BCAR4 could promote DDP resistance of gastric cancer via

Table 8 LncRNAs and platinum drugs resistance in gastric cancer

\begin{tabular}{|c|c|c|c|c|}
\hline LncRNAs & Expression $^{1}$ & Genes and Pathways & Drugs & Reference \\
\hline \multirow[t]{2}{*}{ PCAT-1 } & \multirow[t]{2}{*}{$\uparrow$} & EZH2, PTEN & \multirow[t]{2}{*}{ cisplatin } & {$[161]$} \\
\hline & & miR-128/ZEB1 & & [162] \\
\hline DANCR & $\uparrow$ & $M D R 1, M R P 1$ & cisplatin & {$[163]$} \\
\hline SNHG5 & $\uparrow$ & Bax, MDR1, MRP1, BCl-2 & cisplatin & {$[164]$} \\
\hline GHET1 & $\uparrow$ & $B a x, B C l-2, M D R 1, M R P 1$ & cisplatin & {$[165]$} \\
\hline AK022798 & $\uparrow$ & $M R P 1, P-g p$ & cisplatin & {$[166]$} \\
\hline ANRIL & $\uparrow$ & $M D R 1, M R P 1$ & cisplatin & {$[167]$} \\
\hline UCA1 & $\uparrow$ & miR-27b & cisplatin & [168] \\
\hline HULC & $\uparrow$ & & cisplatin & [169] \\
\hline \multirow[t]{2}{*}{ HOTAIR } & \multirow[t]{2}{*}{$\uparrow$} & miR-126/PI3KAKT/MRP1 & cisplatin & {$[170]$} \\
\hline & & miR-34a, PI3KJAkt,Wnt/ß-catenin & cisplatin & {$[171]$} \\
\hline XLOC_006753 & $\uparrow$ & PIBKJAKT/mTOR & cisplatin & {$[172]$} \\
\hline ZFAS1 & $\uparrow$ & Wnt/B-catenin & cisplatin & {$[173]$} \\
\hline BCAR4 & $\uparrow$ & Wnt & cisplatin & {$[174]$} \\
\hline MALAT1 & $\uparrow$ & miR-23b-3p/ATG12 & cisplatin & {$[175]$} \\
\hline PVT-1 & $\uparrow$ & MDR1, MRP, mTOR, HIF-1a & cisplatin & {$[176]$} \\
\hline BLACAT1 & $\uparrow$ & $m i R-361 / A B C B 1$ & oxaliplatin & {$[179]$} \\
\hline CASC2 & $\downarrow$ & miR-19a & cisplatin & [180] \\
\hline CRAL & $\downarrow$ & miR-505/CYLD/AKT & cisplatin & [181] \\
\hline
\end{tabular}

${ }^{1}$ IncRNAs either up-regulated $(\uparrow)$ or down-regulated $(\downarrow)$ in platinum drugs resistant gastric cancer cells

Note: This table shows 17 IncRNAs whose expression levels and underlying pathways in platinum drugs resistance of gastric cancer. 
Table 9 LncRNAs and adriamycin resistance in gastric cancer

\begin{tabular}{llll}
\hline LnCRNAs & Expression $^{1}$ & Genes and Pathways & Reference \\
\hline HOTAIR & $\uparrow$ & miR-217 & {$[182]$} \\
CASC9 & $\uparrow$ & MDR1 & {$[183]$} \\
MRUL & $\uparrow$ & ABCB1 & {$[184]$} \\
UCA1 & $\uparrow$ & PARP, BCl-2 & {$[185]$} \\
& & miR-27b & {$[168]$} \\
D63785 & $\uparrow$ & miR-422a/MEF2D & {$[186]$} \\
HULC & $\uparrow$ & & {$[169]$} \\
NEAT1 & $\uparrow$ & & {$[187]$} \\
ROR & $\uparrow$ & MRP1 & {$[188]$} \\
\hline
\end{tabular}

${ }^{1}$ IncRNAs up-regulated $(\uparrow)$ in adriamycin resistant gastric cancer cells Note: This table shows 8 IncRNAs whose expression levels and underlying pathways in adriamycin resistance of gastric cancer.

activating the Wnt signaling pathway [173, 174]. LncRNA MALAT1 could function as a sponge RNA of miR-23b-3p and conferred chemoresistance of gastric cancer cells through attenuating the inhibitory effects of miR-23b-3p on expression of autophagy related 12 (ATG12) and promote autophagy of gastric cancer cells [175]. LncRNA PVT1 is another chemoresistance-related gene and has been found to promote DDP resistance through increasing expression of MDR1, MRP, mTOR and hypoxia inducing factor $1 \alpha(H I F-1 \alpha)$ [176-178]. Through regulting the miR-361/ABCB1 axis, IncRNA BLACAT1 has been found to confer oxaliplatin resistance [179].

By contrast, a number of tumor suppressor lncRNAs can reverse platinum drugs resistance of gastric cancer. For instance, significantly diminished expression of lncRNA CASC2 was observed in DDP-resistant gastric cancer tissues and cells. Exogenous expression of lncRNA CASC2 has been found to enhance DDP sensitivity of gastric cancer cells BGC823/DDP and SGC7901/DDP through sponging miR-19a [180]. LncRNA, cisplatin resistance-associated lncRNA (CRAL), has also been identified to be downregulated in DDP-resistant gastric cancer cells. Via sponging endogenous miR-505 to upregulate cylindromatosis (CYLD) expression and subsequently inhibiting AKT activation,

Table 10 LncRNAs and 5-FU resistance in gastric cancer

\begin{tabular}{llll}
\hline LnCRNAs & Expression $^{1}$ & Genes and Pathways & Reference \\
\hline ANRIL & $\uparrow$ & MDR1, MRP1 & {$[167]$} \\
UCA1 & $\uparrow$ & miR-27b & {$[168]$} \\
HULC & $\uparrow$ & & {$[169]$} \\
XLOC_006753 & $\uparrow$ & PI3K/AKT/mTOR & {$[172]$} \\
MALAT1 & $\uparrow$ & miR-23b-3p/ATG12 & {$[175]$} \\
PVT-1 & $\uparrow$ & BCl-2 & {$[178]$} \\
LEIGC & $\downarrow$ & snail, slug, twist, ZEB, vimentin & {$[189]$}
\end{tabular}

${ }^{1}$ IncRNAs either up-regulated $(\uparrow)$ or down-regulated $(\downarrow)$ in 5 -FU resistant gastric cancer cells

Note: This table shows 7 IncRNAs whose expression levels and underlying pathways in 5-FU resistance of gastric cancer.
Table 11 LncRNAs and paclitaxel resistance in gastric cancer

\begin{tabular}{llll}
\hline LncRNAs & Expression $^{1}$ & Genes and Pathways & Reference \\
\hline ZFAS1 & $\uparrow$ & Wnt/B-catenin & {$[173]$} \\
MALAT1 & $\uparrow$ & miR-23b-3p/ATG12 & {$[175]$} \\
PVT-1 & $\uparrow$ & MDR1, MRP, mTOR & {$[177]$} \\
HOTAIR & $\uparrow$ & miR-217 & {$[182]$} \\
CASC9 & $\uparrow$ & MDR1 & {$[183]$}
\end{tabular}

${ }^{1}$ IncRNAs up-regulated $(\uparrow)$ in paclitaxel resistant gastric cancer cells Note: This table shows 5 IncRNAs whose expression levels and underlying pathways in paclitaxel resistance of gastric cancer.

ectopic CRAL expression can weaken DDP resistance of gastric cancer cells by potentiating DDP-induced DNA damage and cell apoptosis in vitro and in preclinical models [181].

\section{LncRNAs and ADR resistance}

Multiple onco-lncRNAs, such as HOTAIR, CASC9, MRUL, UCA1, D63785, NEAT1 and HULC, are involved in ADR resistance in gastric cancer (Table 9). For example, via inhibiting miR-217 expression, lncRNA HOTAIR can promote ADR resistance of gastric cancer cells [182]. LncRNA cancer susceptibility candidate 9 (CASC9), whose expression is associated with poor differentiation, invasion and lymph node metastases of gastric cancer, has been reported to promote resistance to ADR of gastric cancer cells through up-regulating expression of MDR1 protein [183]. MDR-related and upregulated lncRNA (MRUL), which is significantly upregulated in MDR SGC7901/ADR and SGC7901/VCR gastric cancer cells, has been found to promote $\mathrm{ABCB} 1$ expression and, thus, resistance to ADR and VCR [184]. Interestingly, lncRNA UCA1 has been shown to contribute to ADR resistance through regulating apoptosisrelated gene PARP1 and $\mathrm{Bcl}-2$ or via sponging miR-27b $[168,185]$. It has been found that lncRNA D63785, functions as a competitive endogenous RNA (ceRNA) of miR-422a, could promote ADR resistance through blocking miR-422-dependent suppression of myocyte enhancer factor-2D (MEF2D) [186]. In addition, lncRNAs HULC and NEAT1 are also involved in enhancing ADR resistance of gastric cancer cells [169, 187]. Recently, IncRNA regulator of reprogramming (ROR) has been found to confer the resistant to ADR and VCR by up-regulating MRP1 expression in gastric cancer cells and correlated to poor patient outcomes [188].

\section{LncRNAs and 5-FU resistance}

It has been found that several oncogenic or tumor suppressive lncRNAs are involved in 5-FU resistance (Table 10). Among these onco-lncRNAs, ANRIL was highly expressed in 5-FU resistant gastric cancer cells BGC823/5-FU and gastric cancer tissues [167]. LncRNAs 
Table 12 CircRNAs and drug resistance in gastric cancer

\begin{tabular}{lllll}
\hline CircRNAs & Expression $^{1}$ & Genes and Pathways & Related drug & Reference \\
\hline circAKT3 & $\uparrow$ & miR-198/ PIK3R1 & cisplatin & [200] \\
hsa_circ_0081143 & $\uparrow$ & miR-646/CDK6 & cisplatin & [201] \\
circFN1 & $\uparrow$ & miR-182-5p & cisplatin & [202] \\
Circ-PVT1 & $\uparrow$ & miR-124-3p/ZEB1 & paclitaxel & [23] \\
Circ MTHFD2 & $\uparrow$ & miR-124/FDZ5/MDR-1 & pemetrexed & [203] \\
\hline
\end{tabular}

${ }^{1}$ circRNAs up-regulated $(\uparrow)$ in chemo-resistant gastric cancer cells.

Note: This table shows 5 circRNAs whose expression levels and underlying pathways in chemoresistance of gastric cancer.

UCA1 and HULC have also been found to promote 5-FU resistance [168, 169]. XLOC_006753 is an upregulated lncRNA in gastric cancer patients and 5FU resistant cells SGC-7901/5-FU, which is not only correlated with tumor size, metastasis, TNM stage and worse prognosis in gastric cancer patients, but also contributed to 5-FU resistance by influencing cell cycle G1/S transition, apoptosis, some markers of MDR and EMT expression, as well as the PI3K/ AKT/mTOR signaling [172]. Additionally, oncogenic lncRNAs MALAT1 and PVT-1 could contribute to 5-FU resistance of gastric cancer by modulating expression of the miR-23b-3p/ATG12 axis and Bcl-2, respectively $[175,178]$. On the contrary, tumor suppressor lncRNAs can reverse 5-FU resistance in gastric cancer. LncRNA LEIGC has, for example, been found to sensitize gastric cancer cells to 5-FU via inhibiting expression of multiple EMT-related genes [189].

\section{LncRNAs and PTX resistance}

Several oncogenic lncRNAs have been found to promote PTX resistance (Table 11). For example, lncRNA ZFAS1 could enhance PTX resistance of SGC7901 gastric cancer cells by altering the expressions of EMT markers (Ecadherin, N-cadherin, and vimentin) and cell cycle related proteins (cyclin D1, cyclin E and cyclin B1), as well as the $\mathrm{Wnt} / \beta$-catenin signaling [173]. IncRNA MALAT1 has also been found to confer to PTX resistance through targeting miR-23b-3p and ATG12 in gastric cancer cells

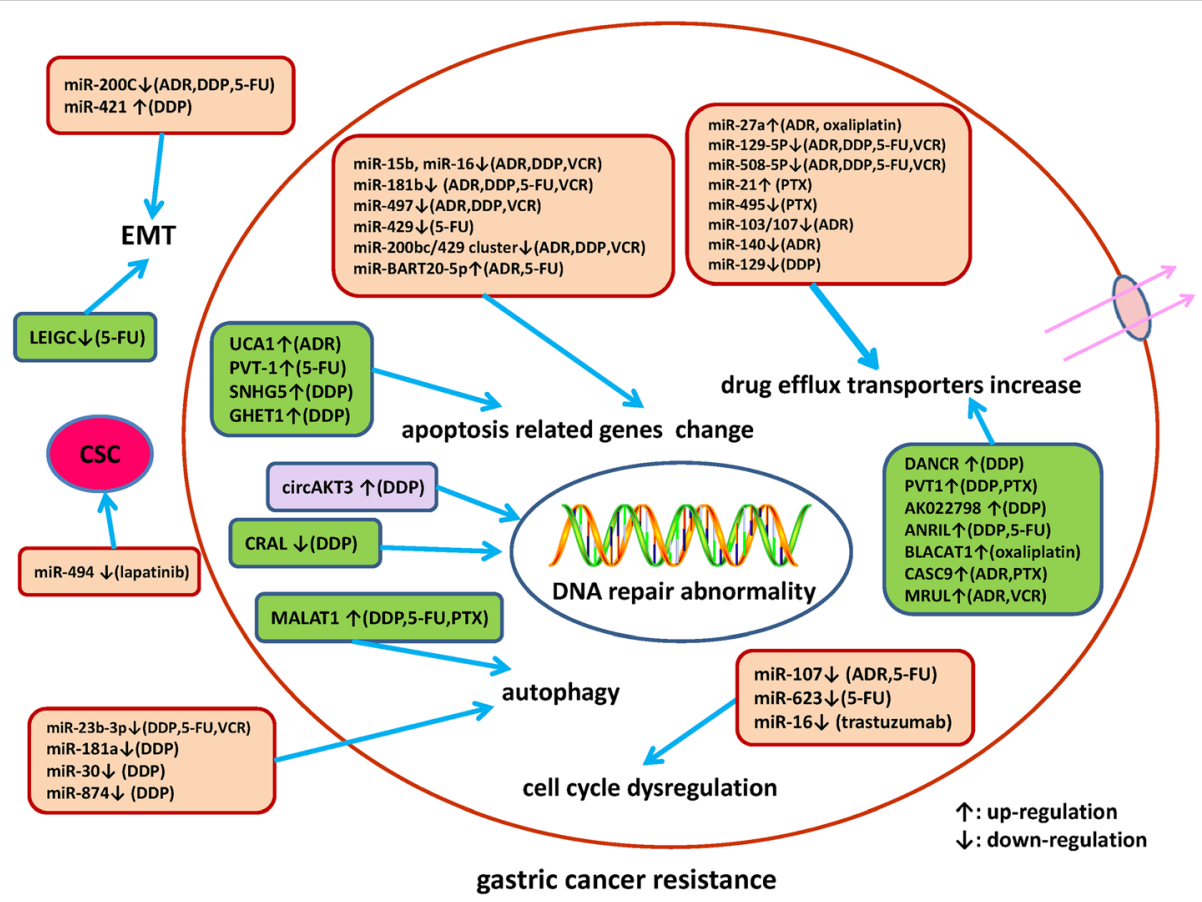

Fig. 1 A summary diagram of miRNAs, IncRNAs and circRNAs participated in the drug resistance of gastric cancer. Several miRNAs, IncRNAs and circRNAs have been found to be involved in gastric cancer drug resistance by influencing apoptosis, DNA repair, cell cycle, proliferation, autophagy, epithelial-mesenchymal transition, and cancer stem cell through regulating expression of potential target genes and related signaling pathway 
[175]. In addition, lncRNAs PVT1 [177], HOTAIR [182] and CASC9 [183] also promoted PTX resistance of gastric cancer through modulating expression of various genes.

\section{CircRNAs and chemoresistance in gastric cancer}

CircRNAs, a new class of ncRNAs with the special ring structure, are stably expressed in multiple cells and once considered as transcriptional splicing intermediates, byproducts or accidental splicing errors. Accumulating evidences indicated that circRNAs play a key regulatory role in cell physiological process and human diseases, including cancer via sponging miRNAs or interacting with various proteins [190-192]. In addition, the annular structure endows circRNAs with inherent stability, which enables them to accumulate in exosomes and exist stably in peripheral body fluids such as plasma and saliva. All these elucidate the potential of circRNAs as markers for diagnosis and therapy of cancers [193-195]. It has been found that circRNAs not only contribute to development and metastasis of malignances, but also are involved in chemoresistance [196-199]. Several oncogenic circRNAs have been found to participate in drug resistance of gastric cancer (Table 12). For instance, circAKT3 (hsa_circ_0000199), which is derived from exons 8, 9, 10 and 11 of the AKT3 gene and highly expressed in DDP-resistant gastric cancer cells and tissues, plays a crucial role in DDP resistance of gastric cancer. It has been found that through up-regulating PIK3R1 by sponging miR-198, circAKT3 could confer DDP resistance of gastric cancer cells. Moreover, circAKT3 could promote DNA damage repair and suppress apoptosis of gastric cancer cells in vitro and in vivo. Additionally, increased expression of circAKT3 was an independent risk factor for disease-free survival (DFS) of gastric cancer patients treated with DDP [200]. Similarly, cirRNA hsa_circ 0081143, which is up-regulated in gastric cancer tissues, could also contribute to DDP resistance by regulating the miR-646/CDK6 pathway. Knockdown of hsa_circ 0081143 inhibited tumorigenesis and remarkably sensitized gastric cancer cells to DDP in vivo. In addition, elevated expression of hsa_circ_0081143 is significantly associated with lymph node metastases, advanced TNM stage and worse overall survival (OS) of gastric cancer patients [201]. Through sponging miR-182-5p, a novel circRNA circFN1 (hsa_circ_0058147, deriving from FN1 gene exons 10,11, and 12) has also been found to promote DDP resistance in gastric cancer [202]. In addition, circRNA circ-PVT1 could facilitate paclitaxel (PTX) resistance of gastric cancer cells via up-regulating ZEB1 mediated by miR-124-3p [23]. Circ MTHFD2, an overexpressed circRNA in pemetrexed (MTA) resistant MGC-803/MTA gastric cancer cells, could enhance the drug resistance of MGC-803/MTA cells by binding to
miR-124 and increased protein expression of FDZ5 and MDR-1 [203].

\section{Conclusions and future perspectives}

An increasing number of ncRNAs have been identified to be involved in drug resistance of gastric cancer. As shown in Figure 1, the underlying mechanisms of drug resistance-related ncRNAs in gastric cancer are summarized. Treatments targeting these abnormally expressed ncRNAs is a promising approach to reverse drug resistance. Exogenous expression of tumor suppressive ncRNAs or knockdown of oncogenic ncRNAs via small interfering RNAs (siRNAs) or short hairpin RNAs (shRNAs) have been investigated to be applicable in reversing drug resistance of gastric cancer. Combination of ncRNAs-based therapeutic interventions with traditional chemotherapy or targeted therapy may be a promising option to conquer drug resistance in advanced gastric cancer patients. Whereas, it is still a challenge how to choose crucial target ncRNAs from a large amount of candidate ncRNAs. Future translational studies or clinical trials are warrant to develop ncRNAs-based therapeutics, which may eventually improve prognosis of gastric cancer patients via overcoming drug resistance.

\section{Abbreviations}

ncRNA: Noncoding RNA; miRNA/miR: MicroRNA; IncRNA: Long noncoding RNA; circRNA: Circular RNA; snRNA: Small nuclear RNA; snoRNA: Small nucleolar RNA; MDR: Multi-drug resistance; CSC: Cancer stem cells; EMT: Epithelial-mesenchymal transition; ADR: Adriamycin; DDP: Cisplatin; 5FU: 5-fluorouracil; VCR: Vincristine; PTX: Paclitaxel; nt: Nucleotide; piRNA: PIWIinteracting RNA; AP-2a: Activating protein 2 alpha; 3'-UTR: 3'-untranslated region; mRNA: Messenger RNA; PTEN: Phosphatase and tensin homologue; BLID: BH3-like motif-containing protein, cell death inducer; EGR2: Early growth response 2; TIMP3: Tissue inhibitor of matrix metalloproteinases 3; FADD: Fas-associated death domain; HDAC: Histone deacetylase; ABCB1: ATP-binding cassette, subfamily B, member 1; ZNRD1: Zinc ribbon domain-containing 1; cav-1: Caveolin-1; HMGA2: High-mobility group AThook 2; EZH2: Enhancer of zeste homolog 2; PDE4D: Phosphodiesterase 4D; SMO: Smoothened; CYLD: Cylindromatosis; KEAP1: Kelch-like ECH-associated protein-1; FBXW7: F-Box and WD repeat domain containing 7;

CAPNS1: Calpain small subunit 1; KLF4: Krüppel-like factor 4;

MST1: Mammalian ste20-like kinase 1; LRIG1: Leucine-rich repeats and immunoglobulin-like domains 1; DAPK2: Death-associated protein kinase 2; ATG12: Autophagy related 12; HMGB2: High mobility group box 2; ANXA2: Annexin A2; SUZ12: Suppressor of zeste 12 protein; FGFR1: Fibroblast growth factor receptor 1; ZEB1: Zinc finger E-box binding homeobox transcription factor 1; ERCC: Excision repair cross-complementing:

TS: Thymidylate synthase; ZH2: Zeste homolog 2; MAPK1: Mitogen-activated protein kinase 1; TAX1BP1: Tax1-binding protein 1; ZNF139: Zing finger 139; CCND1: Cyclin D1; SLC34A2: Solute carrier family 34 member 2; MAPT: Microtubule-associated protein tau; FDA: US Food and Drug Administration; CCNJ: Cyclin J; FUBP1: Far upstream element-binding protein 1; FGFR2: Fibroblast growth factor receptor 2; PCAT-1: Prostate cancerassociated transcript 1; HOTAIR: HOX transcript antisense gene RNA; MALAT1: Metastasis-associated lung adenocarcinoma transcript 1: UCA1: Urothelial carcinoma-associated 1; NEAT1: Nuclear paraspeckle assembly transcript 1; HIF-1a: Hypoxia inducing factor 1a; CIC: Cancer initiation cell; MRUL: MDR-related and upregulated InCRNA; CASC9: Cancer susceptibility candidate 9; ceRNA: Competitive endogenous RNA; MEF2D: Myocyte enhancer factor-2D; DFS: Disease-free survival; OS: Overall survival; siRNA: Small interfering RNA; shRNA: Short hairpin RNA 


\section{Acknowledgements}

Not applicable.

\section{Authors' contributions}

LW and MY conceived the review, acquired data, provided project funding, writing and reviewing the manuscript. All authors contributed to the conception and revision of the manuscript and approved its submission.

\section{Funding}

This study was financially supported by Science and Technology Development Project of Shandong Province (2016GSF201211); Shandong Health Department (2016WS0554); National Natural Science Foundation of China (31671300, 31871306); Taishan Scholars Program of Shandong Province (tsqn20161060); China Postdoctoral Science Foundation (2016M602132); Natural Science Foundation of Shandong Province of China (ZR2017MH050); Medical and Health Science Technology Development Program of Shandong Province of China (2016WS0560). The funding bodies did not play any role in writing the manuscript.

\section{Availability of data and materials}

Not applicable.

\section{Ethics approval and consent to participate}

Not applicable.

\section{Consent for publication}

Not applicable.

\section{Competing interests}

The authors declare that they have no competing interests.

\section{Author details}

'Shandong Provincial Key Laboratory of Radiation Oncology, Cancer Research Center, Shandong Cancer Hospital and Institute, Shandong First Medical University and Shandong Academy of Medical Sciences, Jinan 250117, Shandong Province, China. ²Department of Pathology, Shandong Cancer Hospital and Institute, Shandong First Medical University and Shandong Academy of Medical Sciences, Jinan 250117, Shandong Province, China. ${ }^{3}$ Department of Radiation Oncology, Shandong Cancer Hospital and Institute, Shandong First Medical University and Shandong Academy of Medical Sciences, Jinan 250117, Shandong Province, China.

Received: 14 December 2019 Accepted: 12 March 2020 Published online: 19 March 2020

\section{References}

1. Global Burden of Disease Cancer C, Fitzmaurice C, Dicker D, Pain A, Hamavid H, Moradi-Lakeh M, et al. The Global Burden of Cancer 2013. JAMA Oncol. 2015;1(4):505-27.

2. Nies AT, Magdy T, Schwab M, Zanger UM. Role of ABC transporters in fluoropyrimidine-based chemotherapy response. Adv Cancer Res. 2015;125: 217-43.

3. Hammond WA, Swaika A, Mody K. Pharmacologic resistance in colorectal cancer: a review. Ther Adv Med Oncol. 2016;8(1):57-84

4. Czabotar PE, Lessene G, Strasser A, Adams JM. Control of apoptosis by the $\mathrm{BCL}-2$ protein family: implications for physiology and therapy. Nat Rev Mol Cell Biol. 2014:15(1):49-63.

5. Esteller M, Pandolfi PP. The Epitranscriptome of Noncoding RNAs in Cancer. Cancer Discov. 2017;7(4):359-68.

6. Lu L, Sun J, Shi P, Kong W, Xu K, He B, et al. Identification of circular RNAs as a promising new class of diagnostic biomarkers for human breast cancer. Oncotarget. 2017;8(27):44096-107.

7. Xing F, Wang S, Zhou J. The Expression of MicroRNA-598 Inhibits Ovarian Cancer Cell Proliferation and Metastasis by Targeting URI. Mol Ther Oncolytics. 2019;12:9-15

8. Wang WJ, Li HT, Yu JP, Han XP, Xu ZP, Li YM, et al. A Competing Endogenous RNA Network Reveals Novel Potential IncRNA, miRNA, and mRNA Biomarkers in the Prognosis of Human Colon Adenocarcinoma. J Surg Res. 2019;235:22-33.
9. $\quad$ Mai D, Ding P, Tan L, Zhang J, Pan Z, Bai R, et al. PIWI-interacting RNA54265 is oncogenic and a potential therapeutic target in colorectal adenocarcinoma. Theranostics. 2018;8(19):5213-30.

10. Wang H, Ma P, Liu P, Chen B, Liu Z. Small nucleolar RNA U2_19 promotes hepatocellular carcinoma progression by regulating Wnt/beta-catenin signaling. Biochem Biophys Res Commun. 2018:500(2):351-6.

11. Okugawa Y, Toiyama Y, Toden S, Mitoma H, Nagasaka T, Tanaka K, et al. Clinical significance of SNORA42 as an oncogene and a prognostic biomarker in colorectal cancer. Gut. 2017;66(1):107-17.

12. Yi C, Wan X, Zhang Y, Fu F, Zhao C, Qin R, et al. SNORA42 enhances prostate cancer cell viability, migration and EMT and is correlated with prostate cancer poor prognosis. Int J Biochem Cell Biol. 2018;102:138-50.

13. Vychytilova-Faltejskova P, Stitkovcova K, Radova L, Sachlova M, Kosarova Z, Slaba K, et al. Circulating PIWI-Interacting RNAs piR-5937 and piR-28876 Are Promising Diagnostic Biomarkers of Colon Cancer. Cancer Epidemiol Biomarkers Prev. 2018;27(9):1019-28.

14. Wu L, Zheng J, Chen P, Liu Q, Yuan Y. Small nucleolar RNA ACA1 promotes proliferation, migration and invasion in hepatocellular carcinoma by targeting the PI3K/AKT signaling pathway. Biomed Pharmacother. 2017; 90:705-12.

15. Qin XG, Zeng JH, Lin P, Mo WJ, Li Q, Feng ZB, et al. Prognostic value of small nuclear RNAs (snRNAs) for digestive tract pan- adenocarcinomas identified by RNA sequencing data. Pathol Res Pract. 2019;215(3):414-26.

16. Cech TR, Steitz JA. The noncoding RNA revolution-trashing old rules to forge new ones. Cell. 2014;157(1):77-94.

17. Dhamija S, Diederichs S. From junk to master regulators of invasion: IncRNA functions in migration, EMT and metastasis. Int J Cancer. 2016;139(2):269-80.

18. Wu H, Liu C, Yang Q, Xin C, Du J, Sun F, et al. MIR145-3p promotes autophagy and enhances bortezomib sensitivity in multiple myeloma by targeting HDAC4. Autophagy. 2019;16:1-15.

19. Gao S, Yu Y, Liu L, Meng J, Li G. Circular RNA hsa_circ 0007059 restrains proliferation and epithelial-mesenchymal transition in lung cancer cells via inhibiting microRNA-378. Life Sci. 2019;233:116692.

20. Liu J, Song S, Lin S, Zhang M, Du Y, Zhang D, et al. Circ-SERPINE2 promotes the development of gastric carcinoma by sponging miR-375 and modulating YWHAZ. Cell Prolif. 2019;52(4):e12648.

21. Guo Z, Zhang J, Fan L, Liu J, Yu H, Li X, et al. Long Noncoding RNA (IncRNA) Small Nucleolar RNA Host Gene 16 (SNHG16) Predicts Poor Prognosis and Sorafenib Resistance in Hepatocellular Carcinoma. Med Sci Monit. 2019:25:2079-86.

22. Zhang Q, Zhang C, Ma JX, Ren H, Sun Y, Xu JZ. Circular RNA PIP5K1A promotes colon cancer development through inhibiting miR-1273a. World J Gastroenterol. 2019;25(35):5300-9.

23. Liu YY, Zhang LY, Du WZ. Circular RNA circ-PVT1 contributes to paclitaxel resistance of gastric cancer cells through the regulation of ZEB1 expression by sponging miR-124-3p. Biosci Rep. 2019;39(12):BSR20193045.

24. Chun-Zhi Z, Lei H, An-Ling Z, Yan-Chao F, Xiao Y, Guang-Xiu W, et al. MicroRNA-221 and microRNA-222 regulate gastric carcinoma cell proliferation and radioresistance by targeting PTEN. BMC Cancer. 2010;10: 367.

25. Zhu C, Huang Q, Zhu H. miR-383 Inhibited the Cell Cycle Progression of Gastric Cancer Cells via Targeting Cyclin E2. DNA Cell Biol. 2019;38(8):84956.

26. Zhang F, Li Y, Xu W, He L, Tan Y, Xu H. Long non-coding RNA ZFAS1 regulates the malignant progression of gastric cancer via the microRNA200b-3p/Wnt1 axis. Biosci Biotechnol Biochem. 2019;83(7):1289-99.

27. Xi Z, Si J, Nan J. LncRNA MALAT1 potentiates autophagyassociated cisplatin resistance by regulating the microRNA30b/autophagyrelated gene 5 axis in gastric cancer. Int J Oncol. 2019:54(1):239-48.

28. Lee SD, Yu D, Lee DY, Shin HS, Jo JH, Lee YC. Upregulated microRNA-193a$3 p$ is responsible for cisplatin resistance in CD44(+) gastric cancer cells. Cancer Sci. 2019;110(2):662-73.

29. Liu XH, Sun M, Nie FQ, Ge YB, Zhang EB, Yin DD, et al. Lnc RNA HOTAIR functions as a competing endogenous RNA to regulate HER2 expression by sponging miR-331-3p in gastric cancer. Mol Cancer. 2014;13:92.

30. Wei Y, Liu Z, Fang J. H19 functions as a competing endogenous RNA to regulate human epidermal growth factor receptor expression by sequestering let7c in gastric cancer. Mol Med Rep. 2018:17(2):2600-6.

31. Masuda K, Shoji H, Nagashima K, Yamamoto S, Ishikawa M, Imazeki H, et al. Correlation between immune-related adverse events and prognosis in 
patients with gastric cancer treated with nivolumab. BMC Cancer. 2019; 19(1):974.

32. Aoki M, Shoji H, Nagashima K, Imazeki H, Miyamoto T, Hirano H, et al. Hyperprogressive disease during nivolumab or irinotecan treatment in patients with advanced gastric cancer. ESMO Open. 2019;4(3):e000488.

33. Sunakawa $Y$, Inoue $E$, Matoba $R$, Kawakami $H$, Sato $Y$, Nakajima TE, et al. DELIVER (JACCRO GC-08) trial: discover novel host-related immunebiomarkers for nivolumab in advanced gastric cancer. Future Oncol. 2019; 15(21):2441-7.

34. Bang YJ, Kang YK, Catenacci DV, Muro K, Fuchs CS, Geva R, et al. Pembrolizumab alone or in combination with chemotherapy as first-line therapy for patients with advanced gastric or gastroesophageal junction adenocarcinoma: results from the phase II nonrandomized KEYNOTE-059 study. Gastric Cancer. 2019;22(4):828-37.

35. Bang YJ, Van Cutsem E, Fuchs CS, Ohtsu A, Tabernero J, Ilson DH, et al. KEYNOTE-585: Phase III study of perioperative chemotherapy with or without pembrolizumab for gastric cancer. Future Oncol. 2019;15(9):943-52.

36. Kulangara K, Zhang N, Corigliano E, Guerrero L, Waldroup S, Jaiswal D, et al. Clinical Utility of the Combined Positive Score for Programmed Death Ligand-1 Expression and the Approval of Pembrolizumab for Treatment of Gastric Cancer. Arch Pathol Lab Med. 2019;143(3):330-7.

37. Roviello G, D'Angelo A, Generali D, Pittacolo M, Ganzinelli M, lezzi G, et al. Avelumab in gastric cancer. Immunotherapy. 2019;11(9):759-68.

38. Hause RJ, Pritchard CC, Shendure J, Salipante SJ. Classification and characterization of microsatellite instability across 18 cancer types. Nat Med. 2016;22(11):1342-50.

39. Le DT, Durham JN, Smith KN, Wang H, Bartlett BR, Aulakh LK, et al. Mismatch repair deficiency predicts response of solid tumors to PD-1 blockade. Science. 2017;357(6349):409-13.

40. Rizvi NA, Hellmann MD, Snyder A, Kvistborg P, Makarov V, Havel JJ, et al. Cancer immunology. Mutational landscape determines sensitivity to PD-1 blockade in non-small cell lung cancer. Science. 2015;348(6230):124-8.

41. Ock CY, Keam B, Kim S, Lee JS, Kim M, Kim TM, et al. Pan-Cancer Immunogenomic Perspective on the Tumor Microenvironment Based on PD-L1 and CD8 T-Cell Infiltration. Clin Cancer Res. 2016;22(9):2261-70.

42. Shukla GC, Singh J, Barik S. MicroRNAs: Processing, Maturation, Target Recognition and Regulatory Functions. Mol Cell Pharmacol. 2011;3(3):83-92.

43. Markopoulos GS, Roupakia E, Tokamani M, Chavdoula E, Hatziapostolou M, Polytarchou C, et al. A step-by-step microRNA guide to cancer development and metastasis. Cell Oncol (Dordr). 2017;40(4):303-39.

44. Ebrahimi S, Hashemy SI. MicroRNA-mediated redox regulation modulates therapy resistance in cancer cells: clinical perspectives. Cell Oncol (Dordr). 2019;42(2):131-41.

45. Stuart-Smith K, Vanhoutte PM. Arachidonic acid evokes epitheliumdependent relaxations in canine airways. J Appl Physiol (1985). 1988;65(5): 2170-80.

46. Wei W, Cao W, Zhan Z, Yan L, Xie Y, Xiao Q. MiR-1284 suppresses gastric cancer progression by targeting EIF4A1. Onco Targets Ther. 2019;12:396576.

47. Li M, Gao M, Xie X, Zhang Y, Ning J, Liu P, et al. MicroRNA-200c reverses drug resistance of human gastric cancer cells by targeting regulation of the NER-ERCC3/4 pathway. Oncol Lett. 2019;18(1):145-52.

48. Ning J, Jiao Y, Xie X, Deng X, Zhang Y, Yang Y, et al. miR1385p modulates the expression of excision repair crosscomplementing proteins ERCC1 and ERCC4, and regulates the sensitivity of gastric cancer cells to cisplatin. Oncol Rep. 2019;41(2):1131-9.

49. Chua PJ, Lim JP, Guo TT, Khanna P, Hu Q, Bay BH, et al. Y-box binding protein-1 and STAT3 independently regulate ATP-binding cassette transporters in the chemoresistance of gastric cancer cells. Int J Oncol. 2018; 53(6):2579-89.

50. Kang X, Li M, Zhu H, Lu X, Miao J, Du S, et al. DUSP4 promotes doxorubicin resistance in gastric cancer through epithelial-mesenchymal transition. Oncotarget. 2017:8(55):94028-39.

51. Hong KS, Kim H, Kim SH, Kim M, Yoo J. Calponin 3 Regulates Cell Invasion and Doxorubicin Resistance in Gastric Cancer. Gastroenterol Res Pract. 2019; 2019:3024970

52. Xu Z, Chen L, Xiao Z, Zhu Y, Jiang $H$, Jin $Y$, et al. Potentiation of the anticancer effect of doxorubicinin drug-resistant gastric cancer cells by tanshinone IIA. Phytomedicine. 2018;51:58-67.
53. Zhou W, Tan W, Huang X, Yu HG. Doxorubicin combined with Notch1targeting siRNA for the treatment of gastric cancer. Oncol Lett. 2018;16(3): 2805-12.

54. Zhao X, Yang L, Hu J. Down-regulation of miR-27a might inhibit proliferation and drug resistance of gastric cancer cells. J Exp Clin Cancer Res. 2011;30:55.

55. Pan Y, Ren F, Zhang W, Liu G, Yang D, Hu J, et al. Regulation of BGC-823 cell sensitivity to adriamycin via miRNA-135a-5p. Oncol Rep. 2014;32(6): 2549-56.

56. Kim H, Choi H, Lee SK. Epstein-Barr virus miR-BART20-5p regulates cell proliferation and apoptosis by targeting BAD. Cancer Lett. 2015;356(2 Pt B): 733-42.

57. Wang F, Li T, Zhang B, Li H, Wu Q, Yang L, et al. MicroRNA-19a/b regulates multidrug resistance in human gastric cancer cells by targeting PTEN. Biochem Biophys Res Commun. 2013:434(3):688-94.

58. Xu YC, Liu X, Li M, Li Y, Li CY, Lu Y, et al. A Novel Mechanism of Doxorubicin Resistance and Tumorigenesis Mediated by MicroRNA-501-5pSuppressed BLID. Mol Ther Nucleic Acids. 2018;12:578-90.

59. Liu X, Lu Y, Xu Y, Hou S, Huang J, Wang B, et al. Exosomal transfer of miR501 confers doxorubicin resistance and tumorigenesis via targeting of BLID in gastric cancer. Cancer Lett. 2019;459:122-34.

60. Li X, Zhang Z, Yu M, Li L, Du G, Xiao W, et al. Involvement of miR-20a in promoting gastric cancer progression by targeting early growth response 2 (EGR2). Int J Mol Sci. 2013;14(8):16226-39.

61. Chen J, Zhou C, Li J, Xiang X, Zhang L, Deng J, et al. miR215p confers doxorubicin resistance in gastric cancer cells by targeting PTEN and TIMP3. Int J Mol Med. 2018;41(4):1855-66.

62. Pang X, Zhou Z, Yu Z, Han L, Lin Z, Ao X, et al. Foxo3a-dependent miR-633 regulates chemotherapeutic sensitivity in gastric cancer by targeting Fasassociated death domain. RNA Biol. 2019;16(2):233-48.

63. Shen $Q$, Yao Q, Sun J, Feng L, Lu H, Ma Y, et al. Downregulation of histone deacetylase 1 by microRNA-520h contributes to the chemotherapeutic effect of doxorubicin. FEBS Lett. 2014;588(1):184-91.

64. Wu Q, Yang Z, Xia L, Nie Y, Wu K, Shi Y, et al. Methylation of miR-129-5p CpG island modulates multi-drug resistance in gastric cancer by targeting ABC transporters. Oncotarget. 2014;5(22):11552-63.

65. Shang Y, Zhang Z, Liu Z, Feng B, Ren G, Li K, et al. miR-508-5p regulates multidrug resistance of gastric cancer by targeting $A B C B 1$ and ZNRD1. Oncogene. 2014;33(25):3267-76.

66. Zhang Y, Qu X, Li C, Fan Y, Che X, Wang X, et al. miR-103/107 modulates multidrug resistance in human gastric carcinoma by downregulating Cav-1. Tumour Biol. 2015;36(4):2277-85.

67. Shang Y, Feng B, Zhou L, Ren G, Zhang Z, Fan X, et al. The miR27b-CCNG1P53-miR-508-5p axis regulates multidrug resistance of gastric cancer. Oncotarget. 2016;7(1):538-49.

68. Zou J, Xu Y. MicroRNA-140 Inhibits Cell Proliferation in Gastric Cancer Cell Line HGC-27 by Suppressing SOX4. Med Sci Monit. 2016;22:2243-52.

69. Teng R, Hu Y, Zhou J, Seifer B, Chen Y, Shen J, et al. Overexpression of Lin28 Decreases the Chemosensitivity of Gastric Cancer Cells to Oxaliplatin, Paclitaxel, Doxorubicin, and Fluorouracil in Part via microRNA-107. PLoS One. 2015;10(12):e0143716.

70. Xia L, Zhang D, Du R, Pan Y, Zhao L, Sun S, et al. miR-15b and miR-16 modulate multidrug resistance by targeting $B C L 2$ in human gastric cancer cells. Int J Cancer. 2008;123(2):372-9.

71. Zhu W, Shan X, Wang T, Shu Y, Liu P. miR-181b modulates multidrug resistance by targeting BCL2 in human cancer cell lines. Int J Cancer. 2010; 127(11):2520-9.

72. Zhu W, Zhu D, Lu S, Wang T, Wang J, Jiang B, et al. miR-497 modulates multidrug resistance of human cancer cell lines by targeting BCL2. Med Oncol. 2012;29(1):384-91.

73. Zhu W, Xu H, Zhu D, Zhi H, Wang T, Wang J, et al. miR-200bc/429 cluster modulates multidrug resistance of human cancer cell lines by targeting BCL2 and XIAP. Cancer Chemother Pharmacol. 2012;69(3):723-31.

74. Ji Q, Hao X, Meng Y, Zhang M, Desano J, Fan D, et al. Restoration of tumor suppressor miR-34 inhibits human p53-mutant gastric cancer tumorspheres. BMC Cancer. 2008:8:266.

75. Chen Y, Zuo J, Liu Y, Gao H, Liu W. Inhibitory effects of miRNA-200c on chemotherapy-resistance and cell proliferation of gastric cancer SGC7901/ DDP cells. Chin J Cancer. 2010;29(12):1006-11.

76. Li Q, Wang JX, He YQ, Feng C, Zhang XJ, Sheng JQ, et al. MicroRNA-185 regulates chemotherapeutic sensitivity in gastric cancer by targeting 
apoptosis repressor with caspase recruitment domain. Cell Death Dis. 2014; 5:e1197.

77. Wang P, Li Z, Liu H, Zhou D, Fu A, Zhang E. MicroRNA-126 increases chemosensitivity in drug-resistant gastric cancer cells by targeting EZH2. Biochem Biophys Res Commun. 2016;479(1):91-6.

78. Zhang XL, Shi HJ, Wang JP, Tang HS, Cui SZ. MiR-218 inhibits multidrug resistance (MDR) of gastric cancer cells by targeting Hedgehog/ smoothened. Int J Clin Exp Pathol. 2015;8(6):6397-406.

79. Peng QP, Du DB, Ming Q, Hu F, Wu ZB, Qiu S. MicroRNA 494 increases chemosensitivity to doxorubicin in gastric cancer cells by targeting phosphodiesterases 4D. Cell Mol Biol (Noisy-le-grand). 2018;64(15):62-6.

80. Deng H, Guo Y, Song H, Xiao B, Sun W, Liu Z, et al. MicroRNA-195 and microRNA-378 mediate tumor growth suppression by epigenetical regulation in gastric cancer. Gene. 2013;518(2):351-9.

81. Schenk EL, Mandrekar SJ, Dy GK, Aubry MC, Tan AD, Dakhil SR, et al. A randomized double-blind phase II study of the Seneca Valley Virus (NTX010) vs placebo for patients with extensive stage SCLC (ES-SCLC) who were stable or responding after at least 4 cycles of platinum-based chemotherapy: NCCTG (Alliance) N0923 Study. J Thorac Oncol. 2019;15:110.

82. Sun J, Bao S, Xu D, Zhang Y, Su J, Liu J, et al. Large-scale integrated analysis of ovarian cancer tumors and cell lines identifies an individualized gene expression signature for predicting response to platinum-based chemotherapy. Cell Death Dis. 2019;10(9):661.

83. Zhu M, Zhou X, Du Y, Huang Z, Zhu J, Xu J, et al. miR-20a induces cisplatin resistance of a human gastric cancer cell line via targeting CYLD. Mol Med Rep. 2016;14(2):1742-50

84. Fang Y, Shen H, Li H, Cao Y, Qin R, Long L, et al. miR-106a confers cisplatin resistance by regulating PTEN/Akt pathway in gastric cancer cells. Acta Biochim Biophys Sin (Shanghai). 2013;45(11):963-72.

85. Zhang Y, Lu Q, Cai X. MicroRNA-106a induces multidrug resistance in gastric cancer by targeting RUNX3. FEBS Lett. 2013;587(18):3069-75.

86. Yang SM, Huang C, Li XF, Yu MZ, He Y, Li J. miR-21 confers cisplatin resistance in gastric cancer cells by regulating PTEN. Toxicology. 2013;306: 162-8.

87. He J, Qi H, Chen F, Cao C. MicroRNA-25 contributes to cisplatin resistance in gastric cancer cells by inhibiting forkhead box O3a. Oncol Lett. 2017;14(5): 6097-102.

88. Zhou X, Su J, Zhu L, Zhang G. Helicobacter pylori modulates cisplatin sensitivity in gastric cancer by down-regulating miR-141 expression. Helicobacter. 2014;19(3):174-81.

89. Zhou X, Jin W, Jia H, Yan J, Zhang G. MiR-223 promotes the cisplatin resistance of human gastric cancer cells via regulating cell cycle by targeting FBXW7. J Exp Clin Cancer Res. 2015;34:28.

90. Zhang Y, Xu W, Ni P, Li A, Zhou J, Xu S. MiR-99a and MiR-491 Regulate Cisplatin Resistance in Human Gastric Cancer Cells by Targeting CAPNS1. Int J Biol Sci. 2016;12(12):1437-47.

91. Ge X, Liu X, Lin F, Li P, Liu K, Geng R, et al. MicroRNA-421 regulated by HIF1alpha promotes metastasis, inhibits apoptosis, and induces cisplatin resistance by targeting E-cadherin and caspase-3 in gastric cancer Oncotarget. 2016;7(17):24466-82.

92. Shao L, Chen Z, Soutto M, Zhu S, Lu H, Romero-Gallo J, et al. Helicobacter pylori-induced miR-135b-5p promotes cisplatin resistance in gastric cancer. FASEB J. 2019;33(1):264-74

93. Zhou J, Chen Q. Poor expression of microRNA-135b results in the inhibition of cisplatin resistance and proliferation and induces the apoptosis of gastric cancer cells through MST1-mediated MAPK signaling pathway. FASEB J. 2019:33(3):3420-36.

94. Wang $Z$, Ji F. Downregulation of microRNA-17-5p inhibits drug resistance of gastric cancer cells partially through targeting p21. Oncol Lett. 2018;15(4): 4585-91.

95. Yan R, Li K, Yuan DW, Wang HN, Zhang Y, Dang CX, et al. Downregulation of microRNA-4295 enhances cisplatin-induced gastric cancer cell apoptosis through the EGFR/PI3K/Akt signaling pathway by targeting LRIG1. Int J Oncol. 2018;53(6):2566-78.

96. Li B, Wang L, Li Z, Wang W, Zhi X, Huang X, et al. miR-3174 Contributes to Apoptosis and Autophagic Cell Death Defects in Gastric Cancer Cells by Targeting ARHGAP10. Mol Ther Nucleic Acids. 2017;9:294-311.

97. Zhao Q, Li Y, Tan BB, Fan LQ, Yang PG, Tian Y. HIF-1alpha Induces Multidrug Resistance in Gastric Cancer Cells by Inducing MiR-27a. PLoS One. 2015; 10(8):e0132746.
98. Yan LH, Chen ZN, Li L, Chen J, Wei WE, Mo XW, et al. miR-135a promotes gastric cancer progression and resistance to oxaliplatin. Oncotarget. 2016; 7(43):70699-714.

99. Lu C, Shan Z, Li C, Yang L. MiR-129 regulates cisplatin-resistance in human gastric cancer cells by targeting P-gp. Biomed Pharmacother. 2017;86:450-6.

100. Hu J, Fang Y, Cao Y, Qin R, Chen Q. miR-449a Regulates proliferation and chemosensitivity to cisplatin by targeting cyclin D1 and BCL2 in SGC7901 cells. Dig Dis Sci. 2014;59(2):336-45.

101. Yang M, Shan X, Zhou X, Qiu T, Zhu W, Ding Y, et al. miR-1271 regulates cisplatin resistance of human gastric cancer cell lines by targeting IGF1R, IRS1, mTOR, and BCL2. Anticancer Agents Med Chem. 2014;14(6):884-91.

102. Zhuang M, Shi Q, Zhang X, Ding Y, Shan L, Shan X, et al. Involvement of miR-143 in cisplatin resistance of gastric cancer cells via targeting IGF1R and BCL2. Tumour Biol. 2015;36(4):2737-45.

103. Wang T, Ge G, Ding Y, Zhou X, Huang Z, Zhu W, et al. MiR-503 regulates cisplatin resistance of human gastric cancer cell lines by targeting IGF1R and BCL2. Chin Med J (Engl). 2014;127(12):2357-62.

104. An Y, Zhang Z, Shang Y, Jiang $X$, Dong J, Yu P, et al. miR-23b-3p regulates the chemoresistance of gastric cancer cells by targeting ATG12 and HMGB2. Cell Death Dis. 2015;6:e1766.

105. Zhao J, Nie $Y$, Wang $H$, Lin Y. MiR-181a suppresses autophagy and sensitizes gastric cancer cells to cisplatin. Gene. 2016;576(2 Pt 2):828-33.

106. Du X, Liu B, Luan X, Cui Q, Li L. miR-30 decreases multidrug resistance in human gastric cancer cells by modulating cell autophagy. Exp Ther Med. 2018;15(1):599-605.

107. Li B, Wang W, Li Z, Chen Z, Zhi X, Xu J, et al. MicroRNA-148a-3p enhances cisplatin cytotoxicity in gastric cancer through mitochondrial fission induction and cyto-protective autophagy suppression. Cancer Lett. 2017; 410:212-27.

108. Chang L, Guo F, Wang Y, Lv Y, Huo B, Wang L, et al. MicroRNA-200C regulates the sensitivity of chemotherapy of gastric cancer SGC7901/DDP cells by directly targeting RhoE. Pathol Oncol Res. 2014;20(1):93-8.

109. Jiang T, Dong P, Li L, Ma X, Xu P, Zhu H, et al. MicroRNA-200c regulates cisplatin resistance by targeting ZEB2 in human gastric cancer cells. Onco Rep. 2017;38(1):151-8

110. Bao J, Xu Y, Wang Q, Zhang J, Li Z, Li D, et al. miR-101 alleviates chemoresistance of gastric cancer cells by targeting ANXA2. Biomed Pharmacother. 2017:92:1030-7.

111. Li G, Yang F, Gu S, Li Z, Xue M. MicroRNA-101 induces apoptosis in cisplatin-resistant gastric cancer cells by targeting VEGF-C. Mol Med Rep. 2016;13(1):572-8.

112. Zhang $X L$, Shi HJ, Wang JP, Tang HS, Wu YB, Fang ZY, et al. MicroRNA-218 is upregulated in gastric cancer after cytoreductive surgery and hyperthermic intraperitoneal chemotherapy and increases chemosensitivity to cisplatin. World J Gastroenterol. 2014:20(32):11347-55.

113. Zhang Z, Kong Y, Yang W, Ma F, Zhang Y, Ji S, et al. Upregulation of microRNA-34a enhances the DDP sensitivity of gastric cancer cells by modulating proliferation and apoptosis via targeting MET. Oncol Rep. 2016; 36(4):2391-7.

114. Wen L, Cheng F, Zhou Y, Yin C. MiR-26a enhances the sensitivity of gastric cancer cells to cisplatin by targeting NRAS and E2F2. Saudi J Gastroenterol. 2015;21(5):313-9.

115. Li X, Liang J, Liu YX, Wang Y, Yang XH, Luan BH, et al. miR-149 reverses cisplatin resistance of gastric cancer SGC7901/DDP cells by targeting FoxM1. Pharmazie. 2016;71(11):640-3.

116. Wang J, Xue X, Hong H, Qin M, Zhou J, Sun Q, et al. Upregulation of microRNA-524-5p enhances the cisplatin sensitivity of gastric cancer cells by modulating proliferation and metastasis via targeting SOX9. Oncotarget. 2017;8(1):574-82.

117. Wei X, Gao M, Ahmed Y, Gao M, Liu W, Zhang Y, et al. MicroRNA-362-5p enhances the cisplatin sensitivity of gastric cancer cells by targeting suppressor of zeste 12 protein. Oncol Lett. 2019;18(2):1607-16.

118. Gu J, Li X, Li H, Jin Z, Jin J. MicroRNA-198 inhibits proliferation and induces apoptosis by directly suppressing FGFR1 in gastric cancer. Biosci Rep. 2019; 39(6):BSR20181258.

119. Wang M, Zhang $R$, Zhang S, Xu R, Yang Q. MicroRNA-574-3p regulates epithelial mesenchymal transition and cisplatin resistance via targeting ZEB1 in human gastric carcinoma cells. Gene. 2019;700:110-9.

120. Peng C, Huang K, Liu G, Li Y, Yu C. MiR-876-3p regulates cisplatin resistance and stem cell-like properties of gastric cancer cells by targeting TMED3. J Gastroenterol Hepatol. 2019;34:1711. 
121. Huang H, Tang J, Zhang L, Bu Y, Zhang X. miR-874 regulates multiple-drug resistance in gastric cancer by targeting ATG16L1. Int J Oncol. 2018;53(6): 2769-79.

122. Han X, Zhang JJ, Han ZQ, Zhang HB, Wang ZA. Let-7b attenuates cisplatin resistance and tumor growth in gastric cancer by targeting AURKB. Cancer Gene Ther. 2018;25(11-12):300-8.

123. Song AL, Zhao L, Wang YW, He DQ, Li YM. Chemoresistance in gastric cancer is attributed to the overexpression of excision repair crosscomplementing 1 (ERCC1) caused by microRNA-122 dysregulation. J Cell Physiol. 2019;234(12):22485-92.

124. Xie X, Huang N, Zhang Y, Wei X, Gao M, Li M, et al. MiR-192-5p reverses cisplatin resistance by targeting ERCC3 and ERCC4 in SGC7901/DDP cells. J Cancer. 2019;10(4):1039-51.

125. Longley DB, Harkin DP, Johnston PG. 5-fluorouracil: mechanisms of action and clinical strategies. Nat Rev Cancer. 2003:3(5):330-8.

126. Noordhuis P, Holwerda U, Van der Wilt CL, Van Groeningen CJ, Smid K, Meijer $\mathrm{S}$, et al. 5-Fluorouracil incorporation into RNA and DNA in relation to thymidylate synthase inhibition of human colorectal cancers. Ann Oncol. 2004;15(7):1025-32.

127. Jian B, Li Z, Xiao D, He G, Bai L, Yang Q. Downregulation of microRNA-193$3 p$ inhibits tumor proliferation migration and chemoresistance in human gastric cancer by regulating PTEN gene. Tumour Biol. 2016;37(7):8941-9.

128. Shen J, Niu W, Zhang H, Jun M, Zhang H. Downregulation of MicroRNA-147 Inhibits Cell Proliferation and Increases the Chemosensitivity of Gastric Cancer Cells to 5-Fluorouracil by Directly Targeting PTEN. Oncol Res. 2018; 26(6):901-11.

129. Wu DM, Hong XW, Wang LL, Cui XF, Lu J, Chen GQ, et al. MicroRNA-17 inhibition overcomes chemoresistance and suppresses epithelialmesenchymal transition through a DEDD-dependent mechanism in gastric cancer. Int J Biochem Cell Biol. 2018:102:59-70

130. Zhu P, Zhang J, Zhu J, Shi J, Zhu Q, Gao Y. MiR-429 Induces Gastric Carcinoma Cell Apoptosis Through Bcl-2. Cell Physiol Biochem. 2015;37(4): 1572-80.

131. Korourian A, Roudi R, Shariftabrizi A, Madjd Z. MicroRNA-31 inhibits RhoAmediated tumor invasion and chemotherapy resistance in MKN-45 gastric adenocarcinoma cells. Exp Biol Med (Maywood). 2017;242(18):1842-7.

132. Sun KK, Shen XJ, Yang D, Gan MQ, Liu G, Zhang YF, et al. MicroRNA-31 triggers $\mathrm{G} 2 / \mathrm{M}$ cell cycle arrest, enhances the chemosensitivity and inhibits migration and invasion of human gastric cancer cells by downregulating the expression of zeste homolog 2 ( $\mathrm{ZH} 2$ ). Arch Biochem Biophys. 2019;663: 269-75.

133. Korourian A, Madjd Z, Roudi R, Shariftabrizi A, Soleimani M. Induction of miR-31 causes increased sensitivity to 5-FU and decreased migration and cell invasion in gastric adenocarcinoma. Bratisl Lek Listy. 2019;120(1):35-9.

134. Xiong HL, Zhou SW, Sun AH, He Y, Li J, Yuan X. MicroRNA197 reverses the drug resistance of fluorouracilinduced SGC7901 cells by targeting mitogenactivated protein kinase 1. Mol Med Rep. 2015;12(4):5019-25.

135. Choi H, Lee SK. TAX1BP1 downregulation by EBV-miR-BART15-3p enhances chemosensitivity of gastric cancer cells to 5-FU. Arch Virol. 2017;162(2):36977.

136. Nie H, Mu J, Wang J, Li Y. miR1955p regulates multidrug resistance of gastric cancer cells via targeting ZNF139. Oncol Rep. 2018;40(3):1370-8.

137. Li LQ, Pan D, Chen Q, Zhang SW, Xie DY, Zheng XL, et al. Sensitization of Gastric Cancer Cells to 5-FU by MicroRNA-204 Through Targeting the TGFBR2-Mediated Epithelial to Mesenchymal Transition. Cell Physiol Biochem. 2018:47(4):1533-45.

138. Jiang L, Yang W, Bian W, Yang H, Wu X, Li Y, et al. MicroRNA-623 Targets Cyclin D1 to Inhibit Cell Proliferation and Enhance the Chemosensitivity of Cells to 5-Fluorouracil in Gastric Cancer. Oncol Res. 2018;27(1):19-27.

139. Zhang JX, Xu Y, Gao Y, Chen C, Zheng ZS, Yun M, et al. Decreased expression of miR-939 contributes to chemoresistance and metastasis of gastric cancer via dysregulation of SLC34A2 and Raf/MEK/ERK pathway. Mol Cancer. 2017;16(1):18.

140. Xie L, Zhang Z, Tan Z, He R, Zeng X, Xie Y, et al. MicroRNA-124 inhibits proliferation and induces apoptosis by directly repressing $\mathrm{EZ} \mathrm{H} 2$ in gastric cancer. Mol Cell Biochem. 2014;392(1-2):153-9.

141. Cao W, Wei W, Zhan Z, Xie D, Xie Y, Xiao Q. Regulation of drug resistance and metastasis of gastric cancer cells via the microRNA647-ANK2 axis. Int $J$ Mol Med. 2018;41(4):1958-66.
142. Cao W, Wei W, Zhan Z, Xie Y, Xiao Q. MiR-1284 modulates multidrug resistance of gastric cancer cells by targeting EIF4A1. Oncol Rep. 2016;35(5): 2583-91.

143. Jin B, Liu Y, Wang H. Antagonism of miRNA-21 Sensitizes Human Gastric Cancer Cells to Paclitaxel. Cell Biochem Biophys. 2015;72(1):275-82.

144. Liu X, Ru J, Zhang J, Zhu LH, Liu M, Li X, et al. miR-23a targets interferon regulatory factor 1 and modulates cellular proliferation and paclitaxelinduced apoptosis in gastric adenocarcinoma cells. PLoS One. 2013;8(6): e64707.

145. Shen B, Yu S, Zhang Y, Yuan Y, Li X, Zhong J, et al. miR-590-5p regulates gastric cancer cell growth and chemosensitivity through RECK and the AKT/ ERK pathway. Onco Targets Ther. 2016;9:6009-19.

146. Wang M, Qiu R, Yu S, Xu X, Li G, Gu R, et al. Paclitaxelresistant gastric cancer MGC803 cells promote epithelialtomesenchymal transition and chemoresistance in paclitaxelsensitive cells via exosomal delivery of miR1555p. Int J Oncol. 2019;54(1):326-38.

147. Wu H, Huang M, Lu M, Zhu W, Shu Y, Cao P, et al. Regulation of microtubule-associated protein tau (MAPT) by miR-34c-5p determines the chemosensitivity of gastric cancer to paclitaxel. Cancer Chemother Pharmacol. 2013;71(5):1159-71.

148. Li L, Wu C, Zhao Y. miRNA-34a enhances the sensitivity of gastric cancer cells to treatment with paclitaxel by targeting E2F5. Oncol Lett. 2017;13(6): $4837-42$.

149. Zou Z, Zou R, Zong D, Shi Y, Chen J, Huang J, et al. miR-495 sensitizes MDR cancer cells to the combination of doxorubicin and taxol by inhibiting MDR1 expression. J Cell Mol Med. 2017;21(9):1929-43.

150. Bang YJ, Van Cutsem E, Feyereislova A, Chung HC, Shen L, Sawaki A, et al. Trastuzumab in combination with chemotherapy versus chemotherapy alone for treatment of HER2-positive advanced gastric or gastrooesophageal junction cancer (ToGA): a phase 3, open-label, randomised controlled trial. Lancet. 2010;376(9742):687-97.

151. Fuchs CS, Tomasek J, Yong CJ, Dumitru F, Passalacqua R, Goswami C, et al. Ramucirumab monotherapy for previously treated advanced gastric or gastro-oesophageal junction adenocarcinoma (REGARD): an international, randomised, multicentre, placebo-controlled, phase 3 trial. Lancet. 2014; 383(9911):31-9.

152. Wilke H, Muro K, Van Cutsem E, Oh SC, Bodoky G, Shimada Y, et al. Ramucirumab plus paclitaxel versus placebo plus paclitaxel in patients with previously treated advanced gastric or gastro-oesophageal junction adenocarcinoma (RAINBOW): a double-blind, randomised phase 3 trial. Lancet Oncol. 2014;15(11):1224-35.

153. Kang YK, Boku N, Satoh T, Ryu MH, Chao Y, Kato K, et al. Nivolumab in patients with advanced gastric or gastro-oesophageal junction cancer refractory to, or intolerant of, at least two previous chemotherapy regimens (ONO-4538-12, ATTRACTION-2): a randomised, double-blind, placebocontrolled, phase 3 trial. Lancet. 2017;390(10111):2461-71.

154. Eto K, Iwatsuki M, Watanabe M, Ida S, Ishimoto T, Iwagami S, et al. The microRNA-21/PTEN pathway regulates the sensitivity of HER2-positive gastric cancer cells to trastuzumab. Ann Surg Oncol. 2014;21(1):343-50.

155. Sui $M$, Jiao A, Zhai $H$, Wang $Y$, Wang $Y$, Sun $D$, et al. Upregulation of miR$125 \mathrm{~b}$ is associated with poor prognosis and trastuzumab resistance in HER2positive gastric cancer. Exp Ther Med. 2017;14(1):657-63.

156. Eto $K$, Iwatsuki M, Watanabe M, Ishimoto T, Ida S, Imamura $Y$, et al. The sensitivity of gastric cancer to trastuzumab is regulated by the miR-223/ FBXW7 pathway. Int J Cancer. 2015;136(7):1537-45.

157. Zhou X, Men X, Zhao R, Han J, Fan Z, Wang Y, et al. miR-200c inhibits TGFbeta-induced-EMT to restore trastuzumab sensitivity by targeting ZEB1 and ZEB2 in gastric cancer. Cancer Gene Ther. 2018;25(3-4):68-76.

158. Venturutti L, Cordo Russo RI, Rivas MA, Mercogliano MF, Izzo F, Oakley RH, et al. MiR-16 mediates trastuzumab and lapatinib response in ErbB-2positive breast and gastric cancer via its novel targets CCNJ and FUBP1. Oncogene. 2016;35(48):6189-202.

159. Yu Y, Yu X, Liu H, Song Q, Yang Y. miR494 inhibits cancerinitiating cell phenotypes and reverses resistance to lapatinib by downregulating FGFR2 in HER2positive gastric cancer. Int J Mol Med. 2018;42(2):998-1007.

160. Fan B, Shen C, Wu M, Zhao J, Guo Q, Luo Y. miR-17-92 cluster is connected with disease progression and oxaliplatin/capecitabine chemotherapy efficacy in advanced gastric cancer patients: A preliminary study. Medicine (Baltimore). 2018;97(35):e12007. 
161. Li H, Ma X, Yang D, Suo Z, Dai R, Liu C. PCAT-1 contributes to cisplatin resistance in gastric cancer through epigenetically silencing PTEN via recruiting EZH2. J Cell Biochem. 2020;121(2):1353-61.

162. Guo Y, Yue P, Wang Y, Chen G, Li Y. PCAT-1 contributes to cisplatin resistance in gastric cancer through miR-128/ZEB1 axis. Biomed Pharmacother. 2019;118:109255.

163. Xu YD, Shang J, Li M, Zhang YY. LncRNA DANCR accelerates the development of multidrug resistance of gastric cancer. Eur Rev Med Pharmacol Sci. 2019;23(7):2794-802

164. Li M, Zhang YY, Shang J, Xu YD. LnCRNA SNHG5 promotes cisplatin resistance in gastric cancer via inhibiting cell apoptosis. Eur Rev Med Pharmacol Sci. 2019;23(10):4185-91.

165. Zhang $X, B o P$, Liu L, Zhang X, Li J. Overexpression of long non-coding RNA GHET1 promotes the development of multidrug resistance in gastric cancer cells. Biomed Pharmacother. 2017:92:580-5.

166. Hang Q, Sun R, Jiang C, Li Y. Notch 1 promotes cisplatin-resistant gastric cancer formation by upregulating IncRNA AK022798 expression. Anticancer Drugs. 2015;26(6):632-40.

167. Lan $W G, X u D H, X u C$, Ding $C L$, Ning FL, Zhou YL, et al. Silencing of long non-coding RNA ANRIL inhibits the development of multidrug resistance in gastric cancer cells. Oncol Rep. 2016;36(1):263-70.

168. Fang Q, Chen X, Zhi X. Long Non-Coding RNA (LncRNA) Urothelial Carcinoma Associated 1 (UCA1) Increases Multi-Drug Resistance of Gastric Cancer via Downregulating miR-27b. Med Sci Monit. 2016;22:3506-13.

169. Zhang $Y$, Song $X$, Wang $X$, Hu J, Jiang L. Silencing of LncRNA HULC Enhances Chemotherapy Induced Apoptosis in Human Gastric Cancer. J Med Biochem. 2016;35(2):137-43.

170. Yan J, Dang Y, Liu S, Zhang Y, Zhang G. LncRNA HOTAIR promotes cisplatin resistance in gastric cancer by targeting miR-126 to activate the PI3K/AKT/ MRP1 genes. Tumour Biol. 2016;37(12):16345-55

171. Cheng C, Qin Y, Zhi Q, Wang J, Qin C. Knockdown of long non-coding RNA HOTAIR inhibits cisplatin resistance of gastric cancer cells through inhibiting the PI3K/Akt and Wnt/beta-catenin signaling pathways by up-regulating miR-34a. Int J Biol Macromol. 2018;107(Pt B):2620-9.

172. Zeng L, Liao Q, Zou Z, Wen Y, Wang J, Liu C, et al. Long Non-Coding RNA XLOC 006753 Promotes the Development of Multidrug Resistance in Gastric Cancer Cells Through the PI3K/AKT/mTOR Signaling Pathway. Cell Physiol Biochem. 2018;51(3):1221-36.

173. Xu W, He L, Li Y, Tan Y, Zhang F, Xu H. Silencing of IncRNA ZFAS1 inhibits malignancies by blocking Wnt/beta-catenin signaling in gastric cancer cells. Biosci Biotechnol Biochem. 2018;82(3):456-65.

174. Wang L, Chunyan Q, Zhou Y, He Q, Ma Y, Ga Y, et al. BCAR4 increase cisplatin resistance and predicted poor survival in gastric cancer patients. Eur Rev Med Pharmacol Sci. 2017;21(18):4064-70.

175. YiRen $H$, YingCong Y, Sunwu Y, Keqin L, Xiaochun T, Senrui C, et al. Long noncoding RNA MALAT1 regulates autophagy associated chemoresistance via miR-23b-3p sequestration in gastric cancer. Mol Cancer. 2017;16(1):174.

176. Zhang XW, Bu P, Liu L, Zhang XZ, Li J. Overexpression of long non-coding RNA PVT1 in gastric cancer cells promotes the development of multidrug resistance. Biochem Biophys Res Commun. 2015;462(3):227-32.

177. Ding J, Li D, Gong M, Wang J, Huang X, Wu T, et al. Expression and clinical significance of the long non-coding RNA PVT1 in human gastric cancer. Onco Targets Ther. 2014;7:1625-30.

178. Du P, Hu C, Qin Y, Zhao J, Patel R, Fu Y, et al. LncRNA PVT1 Mediates Antiapoptosis and 5-Fluorouracil Resistance via Increasing Bcl2 Expression in Gastric Cancer. J Oncol. 2019;2019:9325407.

179. Wu X, Zheng Y, Han B, Dong X. Long noncoding RNA BLACAT1 modulates $A B C B 1$ to promote oxaliplatin resistance of gastric cancer via sponging miR361. Biomed Pharmacother. 2018;99:832-8.

180. Li Y, LV S, Ning H, Li K, Zhou X, Xv H, et al. Down-regulation of CASC2 contributes to cisplatin resistance in gastric cancer by sponging miR-19a. Biomed Pharmacother. 2018;108:1775-82.

181. Wang Z, Wang Q, Xu G, Meng N, Huang X, Jiang Z, et al. The long noncoding RNA CRAL reverses cisplatin resistance via the miR-505/CYLD/ AKT axis in human gastric cancer cells. RNA Biol. 2020:1-14. In press.

182. Wang H, Qin R, Guan A, Yao Y, Huang Y, Jia H, et al. HOTAIR enhanced paclitaxel and doxorubicin resistance in gastric cancer cells partly through inhibiting miR-217 expression. J Cell Biochem. 2018;119(9):7226-34.

183. Shang C, Sun L, Zhang J, Zhao B, Chen X, Xu H, et al. Silence of cancer susceptibility candidate 9 inhibits gastric cancer and reverses chemoresistance. Oncotarget. 2017;8(9):15393-8.
184. Wang Y, Zhang D, Wu K, Zhao Q, Nie Y, Fan D. Long noncoding RNA MRUL promotes $\mathrm{ABCB} 1$ expression in multidrug-resistant gastric cancer cell sublines. Mol Cell Biol. 2014;34(17):3182-93.

185. Shang C, Guo Y, Zhang J, Huang B. Silence of long noncoding RNA UCA1 inhibits malignant proliferation and chemotherapy resistance to adriamycin in gastric cancer. Cancer Chemother Pharmacol. 2016;77(5):1061-7.

186. Zhou Z, Lin Z, He Y, Pang X, Wang Y, Ponnusamy M, et al. The Long Noncoding RNA D63785 Regulates Chemotherapy Sensitivity in Human Gastric Cancer by Targeting miR-422a. Mol Ther Nucleic Acids. 2018;12:40519.

187. Zhang J, Zhao B, Chen X, Wang Z, Xu H, Huang B. Silence of Long Noncoding RNA NEAT1 Inhibits Malignant Biological Behaviors and Chemotherapy Resistance in Gastric Cancer. Pathol Oncol Res. 2018;24(1): 109-13.

188. Wang S, Chen W, Yu H, Song Z, Li Q, Shen X, et al. IncRNA ROR Promotes Gastric Cancer Drug Resistance. Cancer Control. 2020;27(1): 1073274820904694

189. Han Y, Ye J, Wu D, Wu P, Chen Z, Chen J, et al. LEIGC long non-coding RNA acts as a tumor suppressor in gastric carcinoma by inhibiting the epithelialto-mesenchymal transition. BMC Cancer. 2014;14:932.

190. Liu WG, Xu Q. Upregulation of circHIPK3 promotes the progression of gastric cancer via Wnt/beta-catenin pathway and indicates a poor prognosis. Eur Rev Med Pharmacol Sci. 2019;23(18):7905-12.

191. Shen Z, Zhou L, Zhang C, Xu J. Reduction of circular RNA Foxo3 promotes prostate cancer progression and chemoresistance to docetaxel. Cancer Lett. 2019:468:88

192. Sun Y, Li X, Chen A, Shi W, Wang L, Yi R, et al. circPIP5K1A serves as a competitive endogenous RNA contributing to ovarian cancer progression via regulation of miR-661/IGFBP5 signaling. J Cell Biochem. 2019;120:19406.

193. Yu J, Ding WB, Wang MC, Guo XG, Xu J, Xu QG, et al. Plasma circular RNA panel to diagnose hepatitis B virus-related hepatocellular carcinoma: A large-scale, multicenter study. Int J Cancer. 2020;146(6):1754-63.

194. Zhao SY, Wang J, Ouyang SB, Huang ZK, Liao L. Salivary Circular RNAs Hsa_ Circ_0001874 and Hsa_Circ_0001971 as Novel Biomarkers for the Diagnosis of Oral Squamous Cell Carcinoma. Cell Physiol Biochem. 2018;47(6):2511-21.

195. Liu YT, Han XH, Xing PY, Hu XS, Hao XZ, Wang Y, et al. Circular RNA profiling identified as a biomarker for predicting the efficacy of Gefitinib therapy for non-small cell lung cancer. J Thorac Dis. 2019;11(5):1779-87.

196. Shao F, Huang M, Meng F, Huang Q. Circular RNA Signature Predicts Gemcitabine Resistance of Pancreatic Ductal Adenocarcinoma. Front Pharmacol. 2018;9:584.

197. Kun-Peng Z, Xiao-Long M, Lei Z, Chun-Lin Z, Jian-Ping H, Tai-Cheng Z. Screening circular RNA related to chemotherapeutic resistance in osteosarcoma by RNA sequencing. Epigenomics. 2018;10(10):1327-46.

198. Yu W, Peng W, Sha H, Li J. Hsa_circ_0003998 Promotes Chemoresistance via Modulation of miR-326 in Lung Adenocarcinoma Cells. Oncol Res. 2019; 27(5):623-8

199. Shang J, Chen WM, Wang ZH, Wei TN, Chen ZZ, Wu WB. CircPAN3 mediates drug resistance in acute myeloid leukemia through the miR-153-5p/miR183-5p-XIAP axis. Exp Hematol. 2019;70:42-54 e3.

200. Huang X, Li Z, Zhang Q, Wang W, Li B, Wang L, et al. Circular RNA AKT3 upregulates PIK3R1 to enhance cisplatin resistance in gastric cancer via miR198 suppression. Mol Cancer. 2019;18(1):71.

201. Xue M, Li G, Fang X, Wang L, Jin Y, Zhou Q. hsa_circ_0081143 promotes cisplatin resistance in gastric cancer by targeting miR-646/CDK6 pathway. Cancer Cell Int. 2019;19:25

202. Huang $X X$, Zhang $Q$, Hu H, Jin $Y$, Zeng $A L$, Xia $Y B$, et al. A novel circular RNA circFN1 enhances cisplatin resistance in gastric cancer via sponging miR182-5p. J Cell Biochem. 2020. In press.

203. Xu QY, Xie MJ, Huang J, Wang ZW. Effect of circ MTHFD2 on resistance to pemetrexed in gastric cancer through regulating expression of miR-124. Eur Rev Med Pharmacol Sci. 2019;23(23):10290-9.

\section{Publisher's Note}

Springer Nature remains neutral with regard to jurisdictional claims in published maps and institutional affiliations. 